\title{
Nanotechnology in dentistry: prevention, diagnosis, and therapy
}

\author{
This article was published in the following Dove Press journal: \\ International Journal of Nanomedicine \\ 8 October 2015 \\ Number of times this article has been viewed
}

\author{
Ensanya Ali Abou Neel ${ }^{1-3}$ \\ Laurent Bozec ${ }^{3}$ \\ Roman A Perez ${ }^{4,5}$ \\ Hae-Won Kim ${ }^{4-6}$ \\ Jonathan C Knowles 3 \\ 'Division of Biomaterials, Operative \\ Dentistry Department, Faculty of \\ Dentistry, King Abdulaziz University, \\ Jeddah, Saudi Arabia; ${ }^{2}$ Biomaterials \\ Department, Faculty of Dentistry, \\ Tanta University, Tanta, Egypt; ${ }^{3} \mathrm{UCL}$ \\ Eastman Dental Institute, Biomaterials \\ and Tissue Engineering, London, UK; \\ ${ }^{4}$ Institute of Tissue Regenerative \\ Engineering (ITREN), ${ }^{5}$ Department of \\ Nanobiomedical Science and BK2I \\ Plus NBM Global Research Center for \\ Regenerative Medicine, ${ }^{6}$ Department \\ of Biomaterials Science, College \\ of Dentistry, Dankook University, \\ Cheonan, Republic of Korea
}

Correspondence: Ensanya Ali Abou Neel Division of Biomaterials, Operative Dentistry Department, Faculty of Dentistry, King Abdulaziz University, PO Box 80209, Jeddah 21589, Saudi Arabia

Mobile +966 596820208

Email eabouneel@kau.edu.sa; e.abouneel@ucl.ac.uk

\begin{abstract}
Nanotechnology has rapidly expanded into all areas of science; it offers significant alternative ways to solve scientific and medical questions and problems. In dentistry, nanotechnology has been exploited in the development of restorative materials with some significant success. This review discusses nanointerfaces that could compromise the longevity of dental restorations, and how nanotechnolgy has been employed to modify them for providing long-term successful restorations. It also focuses on some challenging areas in dentistry, eg, oral biofilm and cancers, and how nanotechnology overcomes these challenges. The recent advances in nanodentistry and innovations in oral health-related diagnostic, preventive, and therapeutic methods required to maintain and obtain perfect oral health, have been discussed. The recent advances in nanotechnology could hold promise in bringing a paradigm shift in dental field. Although there are numerous complex therapies being developed to treat many diseases, their clinical use requires careful consideration of the expense of synthesis and implementation.
\end{abstract}

Keywords: nanotechnology, nanointerfaces, biofilm-related oral diseases, tissue engineering, drug delivery, toxicity

\section{Introduction}

Nanotechnology as a discipline has rapidly expanded into all areas of science as it offers significant alternative ways to solve scientific and medical questions and problems. Nanotechnology is a branch of technology that works on the dimensions of less than $100 \mathrm{~nm}$. It covers objects such as viruses at around $100 \mathrm{~nm}$ size, down to glucose molecules at around $1 \mathrm{~nm}$. Hence, it is very much concerned with structures at the molecular and atomic scale.

Much of the works that have been carried out over the last 20-30 years (when we have seen an explosion in interest in nanotechnology), have been concerned with nanoparticles, and these exemplify very clearly why there is such an interest in nanotechnology and the properties of the materials at these length scales. For example, one can calculate the surface area of $1 \mathrm{~g}$ of powder at different spherical particle diameter sizes, and plotting these data shows that below $\sim 100 \mathrm{~nm}$, the surface area per gram rises exponentially. This leads to a step change in the properties of these materials as properties such as surface energy per gram of material will also change hugely. This massive increase in surface area can be exploited for a wide range of applications. One of the most simplistic exploitations of nanotechnology is in the pharmaceutical industry, where many drugs are poorly or sparingly soluble in aqueous media due to their hydrophobic nature. Reducing the pharmaceutical down to the nanoparticle size range can allow more of the drug to move into solution due to the massive increase in surface area. 
One area of nanotechnology that has been extensively utilized in dentistry is that of nanoparticles in composites. The rationale for utilization of nanoparticles is two-fold: 1) to improve the esthetics by making the materials more translucent and 2) to improve (or at least modify) the wear properties. However, exploitation of nanoparticles in a composite (dental composites or composites more generally) does not come without its technical challenges. Nanoparticles, as already mentioned, can have extremely high surface charge per gram of powder, which can lead to severe and almost permanent agglomeration and which can give rise to rapid loss or non-attainment of expected properties. One good example of this is the processing of carbon nanotubes (CNTs) into polystyrene or perspex. ${ }^{1} \mathrm{CNT}$ incorporation into these polymers (as opposed to conventional glass or carbon fibers) can give much better mechanical properties (or similar properties to the conventional glass or carbon fiber composite), with little loss of the optical properties of the unfilled polymer, and can also impart the additional functionality of improved conductivity, which may be useful. ${ }^{1}$ To achieve similar reinforcing effects, only $0.5-1 \mathrm{wt} \%$ of CNTs need to be added to the polymer to achieve similar mechanical properties to a conventional composite containing 20-30 wt\% reinforcing fiber. But at these very low additions, dispersion must be absolute and complete to achieve the desired properties, and this can be extremely difficult and in some cases impossible to achieve in a cost-effective way as the surface energy keeps the particles adherent and leads to agglomeration in the composite. However, with a careful understanding of the physics and chemistry of the particles, optimal processing may be achieved and the desired properties attained.

Another area where nanotechnology has been exploited is in the use of submicron grain size ceramics for the production of all-ceramic restorations. The logic for using nanometersized powders for the production of ceramic monoliths is esthetics and wear properties and also for maximizing the strength of the ceramic. Processing of technical ceramics with such small grain sizes is technically challenging. Again surface energy plays a major role. During the thermal processing stage for a ceramic, surface energy drives the solid-state sintering process and can lead to sintering occurring easily and rapidly. The small grain size (as well as a non-uniform grain size distribution) can also lead to uncontrolled grain growth and catastrophic loss of mechanical properties. Thus, the synthesis and characterization of the starting material is paramount to achieving the properties required.

The aim of this review paper is not to cover all areas of nanotechnology as this would not be achievable within a single review, but to focus on some areas that have technical challenges (eg, oral biofilm and cancers), and to highlight how these challenges have been overcome. The recent advances in oral health-related preventive, diagnostic, and therapeutic methods that could hold promise in bringing a paradigm shift in dentistry are the main focus of this review. The clinical implementation of these advances requires careful consideration of the expense of synthesis and possible nanotoxicity. Since nanotoxicity is a general issue, it has been extensively reviewed elsewhere in literature. ${ }^{2-4}$

\section{Bio-nanointerfaces of clinical significance}

To restore partial (enamel and dentin) or complete tooth loss, dental composite or implants are normally used. The retention of resin composite or dental implants is obtained mainly through micromechanical retention. The interface between resin composites and dental tissues or between dental implants and bone is therefore important for the success of these restorations. Looking at the structure of enamel, dentin, and bone, they are composed of organic matrix, mainly collagen and noncollagenous proteins and hydroxyapatite (HA). The ratio of the organic to mineral phase varies according to the tissue. This section reviews the importance of resin composite-tooth as well as implant-bone interface and how nanotechnology has been employed to modify these interfaces to increase the longevity of resin composites and dental implants, respectively.

\section{Adhesive resin-dentin interface}

Bonding of dental composites to tooth structure is obtained through different adhesive resin systems that depend on separate or combined use of etchant, primer, and adhesive resin. ${ }^{5}$ The etchant selectively removes the HA crystals, a natural shelter around collagen-rich demineralized dentin (Figure 1). ${ }^{6,7}$ The unprotected collagen network is then more vulnerable to enzymatic degradation by endogenous matrix metalloproteinases (MMPs) ${ }^{8}$ and cysteine cathepsins ${ }^{9,10}$ that are released from demineralized collagen. The primer helps the subsequent penetration of the adhesive resin. After its polymerization, the entanglement of the adhesive resin into demineralized collagen network creates a transitional zone called hybrid layer or inter-diffusion zone of resin-reinforced collagen. ${ }^{11}$ The polymerized adhesive resin helps to protect the collagen from enzymatic degradation; and the long-term success of resin composites depends on the integrity and durability of adhesive resin-dentin interface. The durability of resin-dentin interface can be jeopardized by: 1) degradation of collagen matrix; 2) incomplete penetration and polymerization of resin monomer; and c) hydrolysis of the 


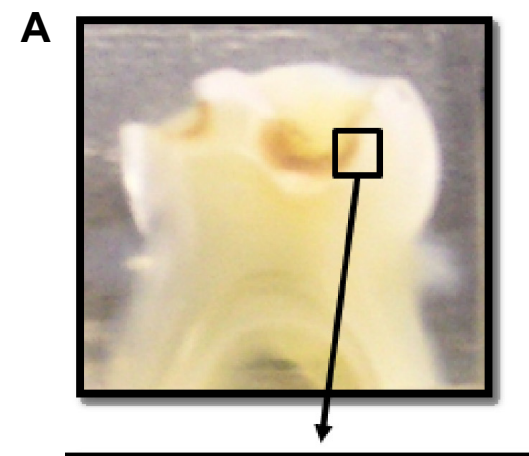

B
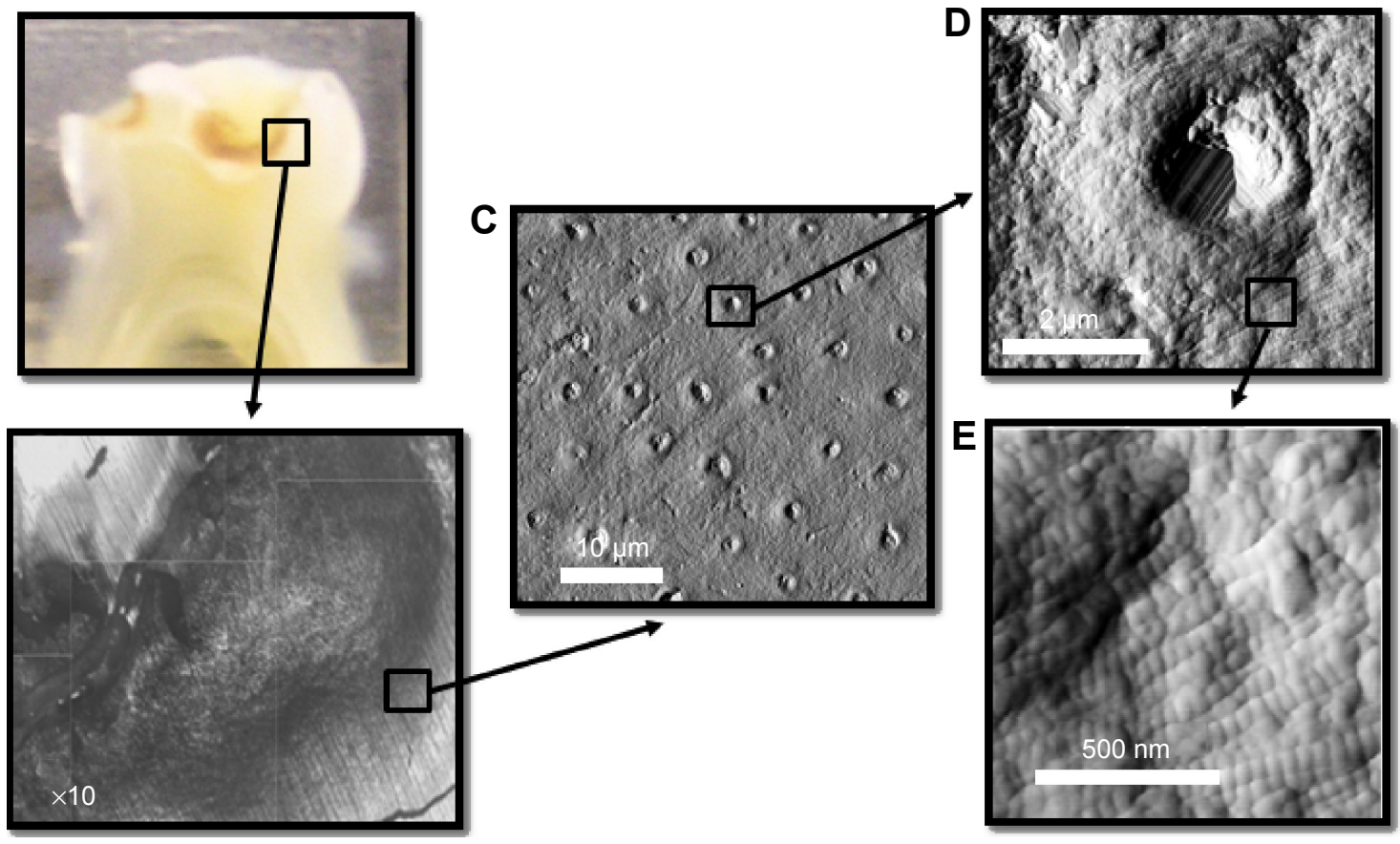

Figure I (A) Optical image of a transverse section of a molar displaying an occlusal cavity, (B) reconstructed optical image of the demineralized region of the dentin in the cavity, and (C) AFM image (deflection) of a single dentin tubule from the demineralized region. Aligned collagen fibrils can be observed wrapping around the tubule. (D) Higher resolution AFM image of the exposed collagen in the vicinity of the dentin tubule; the D-banding periodicity of collage can be clearly resolved as presented in (E). Abbreviation: AFM, atomic force microscopy.

resin monomer. Compromised interface integrity leads to nanoleakage, which occurs as spotted, reticular type and water trees at the hybrid or adhesive layer. ${ }^{12,13}$ The nanoleakge is always associated with pain, sensitivity, recurrent decay, and finally failure of restorations. Nanotechnology has been adopted to extend the longevity of resin-dentin bond via: 1) protection of exposed collagen through reinforcement, cross-linking, and biomimetic remineralization; 2) inhibiting the action of MMPs; and 3) modifying the adhesive resin monomer (Figure 2).

Protection of exposed collagen networks by reinforcement with nanofillers or nanogels has been attempted. In addition to their protective action, these nanofillers or nanogels could help in mineral deposition and hence possible interference with MMPs. ${ }^{14}$ Examples include zirconia $(20-50 \mathrm{~nm}),{ }^{15} \mathrm{HA}$ $(20-70 \mathrm{~nm}),{ }^{16}$ colloidal silica $(5-40 \mathrm{~nm})$ or barium aluminosilicate nanofillers $(400 \mathrm{~nm}),{ }^{17}$ reactive nanogels,${ }^{18}$ and bioactive calcium/sodium phosphosilicate ${ }^{14}$ Cross-linking could also improve the nanomechanical properties of the exposed collagen network ${ }^{19,20}$ and hence reduce its degradation by MMPs. ${ }^{20}$ Examples of cross-linking agents include tannic acid, ${ }^{21}$ combinations of riboflavin and ultraviolet radiation, ${ }^{19}$ riboflavin and/or chitosan, ${ }^{22}$ glutaraldehyde, ${ }^{20}$ grape seed extract, ${ }^{20}$ and proanthocyanidins. ${ }^{23}$ Biomimetic remineralization is a recent approach to protect resin-free, acid-etched dentin. This approach relies on the use of fluidic amorphous nanoprecursors (eg, Portland cement/simulated body fluid/polyacrylic acid/poly(vinylphosphonic acid). These nanoprecursors can be transformed into mesoscopic crystalline intermediates that eventually fuse to form single

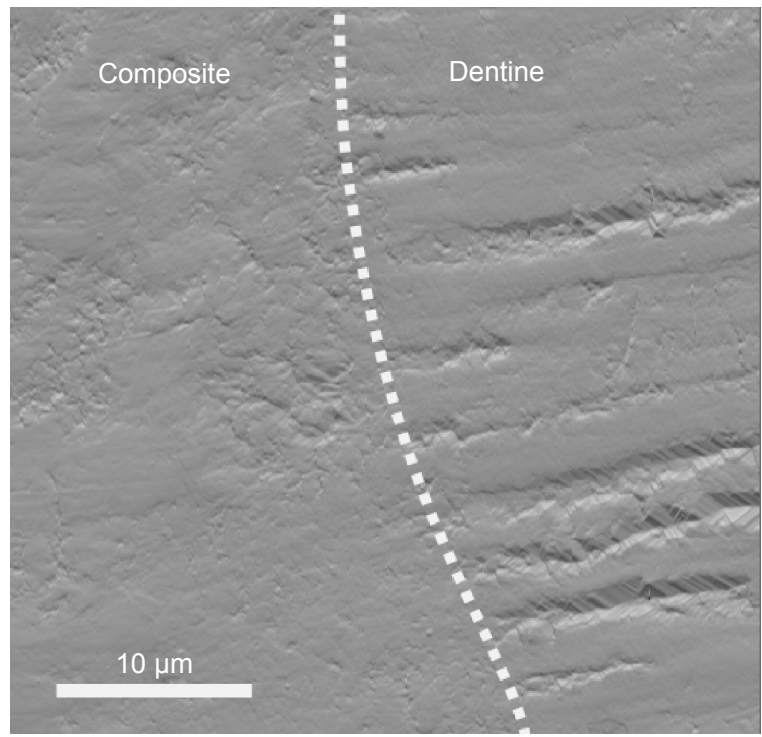

Figure 2 AFM image (deflection) of the interface between a dental composite and dentin.

Notes: The dental composite appears very homogeneous, whereas the crosssectional cut of dentin can be seen throughout the dentin part. The interface shows no apparent gaps. Compromised interface integrity, however, leads to nanoleakage that is always associated with pain, sensitivity, recurrent decay, and finally, failure of restorations.

Abbreviation: AFM, atomic force microscopy. 
microscopic crystals, ie, a bottom-up nanotechnology approach. This technique proved to be successful in remineralizing both interfibrillar and intrafibrillar collagen after 2-4 months and maintaining the nanomechanical properties of normal dentin. It could also help in closing the porosity of the adhesive layer. ${ }^{24,25}$

Inhibition of MMPs action and hence collagen degradation has been also attempted to improve the longevity of the resin-dentin interface. The MMP inhibitor has been used as a separate dentin preconditioning step or included within the resin adhesive monomer. Examples of these inhibitors include benzalkonium chloride, ${ }^{8}$ galardin, ${ }^{26}$ BB94 and GM6001, ${ }^{27}$ chlorhexidine digluconate ${ }^{28,29}$ and $\mathrm{ZnO}$ particles, ${ }^{30}$ ethylenediaminetetraacetic acid, ${ }^{31}$ sodium oxalate, ${ }^{32}$ titanium tetrafluoride and caffeic acid phenethyl ether, ${ }^{33}$ and phosphoric acid/sodium hypochlorite $(\mathrm{NaOCl})$ mixture. ${ }^{34}$

Self-healing adhesives, capable of closing micro- or nanocracks before destroying the integrity of resin-dentin bonds, have been also introduced. ${ }^{35}$ They contain healing agent-filled nanocapsules; the rupture of the nanocapsules and hence the release of their content is usually initiated by the presence of a crack in the resin matrix. ${ }^{36}$ Nanocontrolled molecular interaction between the resin monomer and HA remaining within the hybrid layer has also been employed for improving the longevity of the resin-dentin interface. ${ }^{6}$

\section{Dental implant-bone interface}

The implant-tissue interface is a key for the success of dental implants. Peri-implant healing proceeds from recruitment and migration of bone cells to the implant surface through the action of persistent blood clot, ie, osteoconduction phase to de novo bone formation and finally bone remodeling. Both osteoconduction and de novo bone formation are essential for providing contact osteogenesis. ${ }^{37}$ An intimate contact of the implant at its neck with the surrounding gingival tissue is essential for prevention of bacterial invasion and growth. Getting a fusion of the implant root with the surrounding bone at both structural and functional levels, ie, osseointegration, is crucial for the success of dental implant. ${ }^{38}$ Implant osseointegration is first achieved through primary mechanical and then biological anchorage.$^{39}$ Microscale modification of topography and chemistry of the implant surface indirectly affected implant osseointegration, and it could inevitably induce changes at the nanoscale level. ${ }^{40}$ Since cells can directly interact with nanoscale features, nanotechnology has been introduced to mediate bone formation and implant osseointegration. ${ }^{41}$ Nanoscale modification of dental implant surfaces may include both surface topography as well as chemistry.
Regarding the surface topography of dental implants, several methods, eg, lithography, ionic implantation, anodization, ${ }^{42}$ and radio-frequency plasma treatments, have been used to induce controlled nanosurface features (eg, tubes, ${ }^{43,44}$ dots, ${ }^{45}$ and nodules ${ }^{46}$ ) on dental implants. These features can be arranged in an organized (isotropic) or random (anisotropic) manner to induce altered physicochemical behavior (eg, bone bonding) or specific biochemical events (eg, altered protein adsorption and cell behavior). ${ }^{47}$ Controlling the dimension and spaces between the surface nanofeatures/patterns changed cell behavior since cells are able to sense the surface and adjust their response accordingly. Changing the diameter of nanotubes from $30 \mathrm{~nm}$ to 70-100 nm caused the transition of cell behavior from adhesion to differentiation. ${ }^{43,44} \mathrm{~A}$ spacing between the nanofeatures of $58 \mathrm{~nm}$ promoted the formation of a stable focal adhesion and hence persistence of cell spreading, while $108 \mathrm{~nm}$ spacing produced delayed cell spreading. ${ }^{45}$ Regarding the bone-implant contact, higher density and curvature of $60 \mathrm{~nm}$ features demonstrated higher bone-implant contact than 120 nm features. ${ }^{48}$

Since dental implants contact both hard and soft tissues, these implants must therefore have optimum surface biocompatibility with the host tissue. Accordingly, changing the surface chemistry could also be another option to enhance osteogenesis. Biofunctionalization, ie, immobilization of specific, active biomolecules known for their central role in osteogenesis on the surface of implants, was found to be highly effective in promoting firm and rapid osseointegration. ${ }^{49}$ Examples of these biomolecules include adhesion molecule (RGD) ${ }^{50}$ peptide, alkaline phosphatase,${ }^{49}$ extracellular matrix (ECM) proteins, ${ }^{51}$ and calcium phosphate $(\mathrm{CaP})$ coating. ${ }^{52}$ Bone morphogenetic protein (BMP) has been also immobilized on the surface of dental implants to enhance bioactivity and hence bone formation. ${ }^{53}$ BMP allows controlled administration and avoids overdosing. In this respect, coating the implant surface with nanocrystalline diamonds increased the surface area and facilitated immobilization of BMP. ${ }^{54}$ In such a case, the overall texture of the implant can be maintained, while the cellular proliferation and differentiation were improved. ${ }^{55}$ Immobilization of therapeutic agents that induce osteogenesis, eg, bisphosphonates and simvastatin, ${ }^{56}$ or prevent bacterial infection, eg, silver ${ }^{57}$ and zinc oxide nanoparticles, ${ }^{58}$ into the biofunctionalized implant surface has also been attempted.

Accordingly, for successful dental implants, two conflicting properties (ie, enhancement of protein adsorption 
for cell adhesion but at the same time inhibition of bacterial colonization and hence biofilm formation) are required..$^{59}$ To develop this intelligent implant, which will interact with the continuously changing environment, deliver the appropriate molecule or drug or protein when required, and actively direct cell behavior, very challenging robust techniques and reliable in vivo experiments are required.

\section{Preventive nanodentistry}

Modern dentistry's goal is to prevent rather than treat biofilmdependent oral diseases, eg, dental caries and endodontic and periodontal diseases. Nanotechnology offers new approaches for preventive therapies in oral diseases, particularly dental caries and periodontal diseases.

\section{Dental caries}

Dental caries is one of the most prevalent destructive diseases affecting tooth structures. It is caused by bacteria, eg, Streptococcus mutans, Streptococcus sobrinus, and Lactobacillus spp. These bacteria are usually present in aggregates attached to each other and to tooth surfaces in the form of oral biofilms or dental plaques. They produce acids that cause demineralization of tooth structures, ie, loss of calcium $(\mathrm{Ca})$ and phosphate $\left(\mathrm{PO}_{4}\right)$. Controlling dental caries can be therefore gained through inhibiting the bacterial action, reversing the demineralization process, and promoting remineralization. Development of anti-caries vaccines has also been attempted in this respect.

\section{Antibacterial nanotherapy}

Several nanoparticles (eg, zinc oxide, ${ }^{60,61}$ silver, ${ }^{62-64}$ and polyethylenimine ${ }^{65}$ ) have been incorporated into dental composites $^{66}$ or dental adhesives ${ }^{67}$ to inhibit the bacterial growth through several mechanisms. These mechanisms include disruption of the bacterial cell membrane, ${ }^{68}$ inhibition of the active transport as well as the metabolism of sugars, generation of reactive oxygen species, ${ }^{69}$ displacement of magnesium ions required for the enzymatic activity of oral biofilms, ${ }^{70}$ disturbance of the electron transportation across the bacterial membrane, ${ }^{63}$ and prevention of DNA replication. ${ }^{71}$ These nanoparticles were effective in reducing the $S$. mutans and Lactobacillus acidophilus biofilms in an in vitro model. ${ }^{72,73}$ Coating tooth surfaces with antibacterial nanocoating was found to be effective in killing bacteria as well as inhibiting bacterial adhesion and maintaining its integrity in the presence of biological fluids (saliva). ${ }^{74}$ The antibacterial action of these nanoparticles was shown to be size dependent. ${ }^{75}$
Biomimetic remineralization - reversing an incipient caries

Owing to their colloidal particle size and potential for delivery of calcium ions, calcium carbonate (CC) nanoparticles can have good retention on oral surfaces. They act as a delivery vehicle for slow continuous release of high concentrations of calcium ions into the surrounding oral fluids (saliva and dental plaque). CC nanoparticles also have the potential to increase the surrounding fluid $\mathrm{pH}$. Accordingly, $\mathrm{CC}$ nanoparticles were effective in remineralizing incipient enamel lesions when incorporated into an experimental tooth dentifrice. ${ }^{76}$ Nanosized calcium fluoride $\left(\mathrm{CaF}_{2}\right)$, as a labile reservoir for fluoride $(\mathrm{F})$, has been shown to be highly soluble and reactive with dicalcium phosphate dihydrate compared to its macro counterpart. Owing to its high solubility, a great amount of $\mathrm{CaF}_{2}$ could be consumed by its reaction with dicalcium phosphate dihydrate, and accordingly, a high level of $F$ could be incorporated into the stable reaction product (apatite). Accordingly, a mouth rinse containing nanosized $\mathrm{CaF}_{2}$ showed higher F deposition $\left(2.2 \pm 0.3 \mu \mathrm{g} / \mathrm{cm}^{2}\right)$ than the conventional sodium fluoride $(\mathrm{NaF})$ rinse $\left(0.31 \pm 0.06 \mu \mathrm{g} / \mathrm{cm}^{2}\right)$. The $\mathrm{CaF}_{2}$ rinse could potentially be used as an anticaries agent by increasing the $\mathrm{F}^{-}$concentration in oral fluids and thus enhancing tooth remineralization.

\section{Biomimetic remineralization - recurrent decay}

Since $\mathrm{Ca}^{2+}$ and $\mathrm{PO}_{4}{ }^{3-}$ are prerequisites for remineralization, several $\mathrm{Ca}^{2+}$ - and $\mathrm{PO}_{4}{ }^{3-}$-releasing dental nanocomposites were developed for their remineralizing action; they therefore help in preventing recurrent (secondary) decay around or under restorations. Different forms of nanocalcium phosphates were used as $\mathrm{Ca}^{2+}$ - and $\mathrm{PO}_{4}{ }^{3-}$-releasing fillers, eg, dicalcium phosphate anhydrous, ${ }^{77,78}$ tetracalcium phosphate, ${ }^{79}$ monocalcium phosphate monohydrate, ${ }^{80}$ and carbonate hydroxyapatite. ${ }^{81}$ The release of $\mathrm{Ca}$ and $\mathrm{PO}_{4}$ is dependent on degradability and volume fraction of $\mathrm{CaP}$ form. ${ }^{80}$ Regardless of $\mathrm{Ca}$ and $\mathrm{PO}_{4}$ release, these nanocomposites could be still used for high-stress bearing applications since these nanoparticles are used in combination with other fillers, eg, whiskers fused with nanosized silica. The $\mathrm{Ca}^{2+}$ and $\mathrm{PO}_{4}{ }^{3-}$ can also be released on demand, ie, when the $\mathrm{pH}$ has been reduced from neutral to cariogenic level, and the level of their release increased dramatically with acidic pH. ${ }^{79}$ Thanks to the chemical binding ability of nanocalcium phosphate fillers, eg, carbonate hydroxyapatite, these nanoparticles bind to eroded enamel and dentin, forming a protective coating, and then reverse the action of acid or bacterial attack. ${ }^{81}$ 


\section{Caries vaccine}

Several attempts are currently underway in developing an effective anticaries vaccine as a new strategy of preventing the occurrence of dental caries. DNA vaccine was found to be an effective, safe, stable, and inexpensive immunogenic strategy in inducing both humoral and cellular immune responses. ${ }^{82}$ Many candidate anticaries DNA vaccines have been or are undergoing usage tests in animals or human beings. Examples of these vaccines include pcDNA3-Pac, ${ }^{83}$ pCIA-P ${ }^{84}$ pGJGLU/ VAX, ${ }^{85}$ and pGLUA-P. ${ }^{86}$ Most of the anticaries vaccines work by preventing bacterial accumulation either by blocking the surface protein antigen PAc or inactivation of glucosyltransferases enzyme.${ }^{87}$ Both surface protein antigen PAc and glucosyltransferases are the virulent factors responsible for the adhesion of S. mutans to tooth surfaces. ${ }^{88,89}$ DNA vaccines, however, have poor immunogenicity in large animals and human beings. Nanotechnology has been employed to tailor delivery vehicles (eg, anionic liposomes in chitosan/DNA nanoparticle complex was used as a delivery vehicle ${ }^{90}$ ) to enhance the immunogenicity of anticaries DNA vaccine. Furthermore, the surface charge of the delivery vehicle could be $\mathrm{pH}$ dependent to enable the release of the vaccine in a $\mathrm{pH}$-dependent manner. ${ }^{90}$

Despite the advances in nanotechnology, its clinical application for caries therapy is not yet feasible. Although, the $\mathrm{Ca}^{2+}$ - and $\mathrm{PO}_{4}{ }^{3-}$-releasing nanocomposites have load-bearing capability, their mechanical behavior as $\mathrm{Ca}^{2+}$ and $\mathrm{PO}_{4}{ }^{3-}$ ions being released is difficult to estimate and control under identical clinical situations. The profile of ions released under constrained conditions has not been investigated. A balance between the ion release and the rate of caries progression, which is unpredictable, must exist. The optimum particle size of nanofillers required for remineralization, the pattern in which the released ions are precipitated, and the orientation of precipitated nanocrystals in relation to collagen fibrils are important factors that require careful consideration in designing nanomaterials. Until now, all in vitro investigations indicated that nanotechnology could be effective in reversing lesion progression in the outer but not in the deeper part of early caries lesions. ${ }^{91}$ Controlling deep and large lesions, however, requires a thorough understanding of the caries progression process. Furthermore, incorporation of nanofillers within dental composites might be effective in preventing recurrent caries around restorations; the effect of these nanofillers, however, on bacteria left in affected dentin, which are sometimes left in deep cavities during conservation of tooth structures, has to be studied. Furthermore, regardless of the progress with anticaries vaccinations, their use in human beings has not been tried yet. Accordingly, there is no vaccine available on the market yet. The high diversity of oral flora, high salivary flow, difficult antigen delivery, enzymatic degradation of vaccine, and poor internalization could be limiting factors.

\section{Periodontal diseases}

Nanotechnology has been used to prevent bone loss in an experimental periodontal disease model by local application of nanostructured doxycycline gel. ${ }^{92}$ Nanorobots (dentifrobots) mouthwash or toothpaste left on the occlusal surfaces of teeth with their continuous and fast movement $(1-10 \mu \mathrm{m} /$ second) across the supra and subgingival surfaces continuously removes the organic residues and prevents the calculus accumulation. These nanorobots can be safely deactivated when they are swallowed. ${ }^{93}$

\section{Diagnostic nanodentistry}

Considering the impact of nanotechnology in the fields of drug delivery and diagnostic and novel material design for implantology and tissue regeneration, one may expect the same level of engagement of this emerging field in dentistry. However to date, there have been very few contributions from the scientific and clinical communities reporting an impact of nanotechnology on the diagnostics of dental conditions. Diagnostics of dental conditions is still nowadays routinely undertaken in clinic using a set of guidelines drawn by the best practice in the field. Some of these guidelines have not changed in decades for certain ailments such as caries or tooth crack syndrome for example. It has therefore proven difficult to bring innovative approaches when establishing a treatment plan for patients while ensuring best outcomes. Thus, unlike in medicine, dentistry has not yet seen considerable transition from research laboratory practices to clinical chairs. Nonetheless, over the past few decades, contributions arising from nanotechnology in dentistry have been made mostly in three fields: atomic force microscopy (AFM), imaging contrast enhancers, and biochips.

\section{AFM and oral biofilms}

Thorough understanding of bacterial adhesion, the main factor for bacterial colonization and pathogenesis, as well as bacterial nanomechanics is essential for prevention or treatment of biofilm-dependent oral diseases. ${ }^{67}$ Bacteria have the ability to adhere to others from the same or different species as well as to different substrates, eg, teeth and implants. ${ }^{94,95}$ With the recent technologies, AFM, with its capability to directly interact with and image live cells without any disruption of their morphology and properties, ${ }^{96}$ offers a breakthrough in characterization of bacteria as well as measurement of their adhesion to different substrates (Figure 3). ${ }^{97,98}$ 

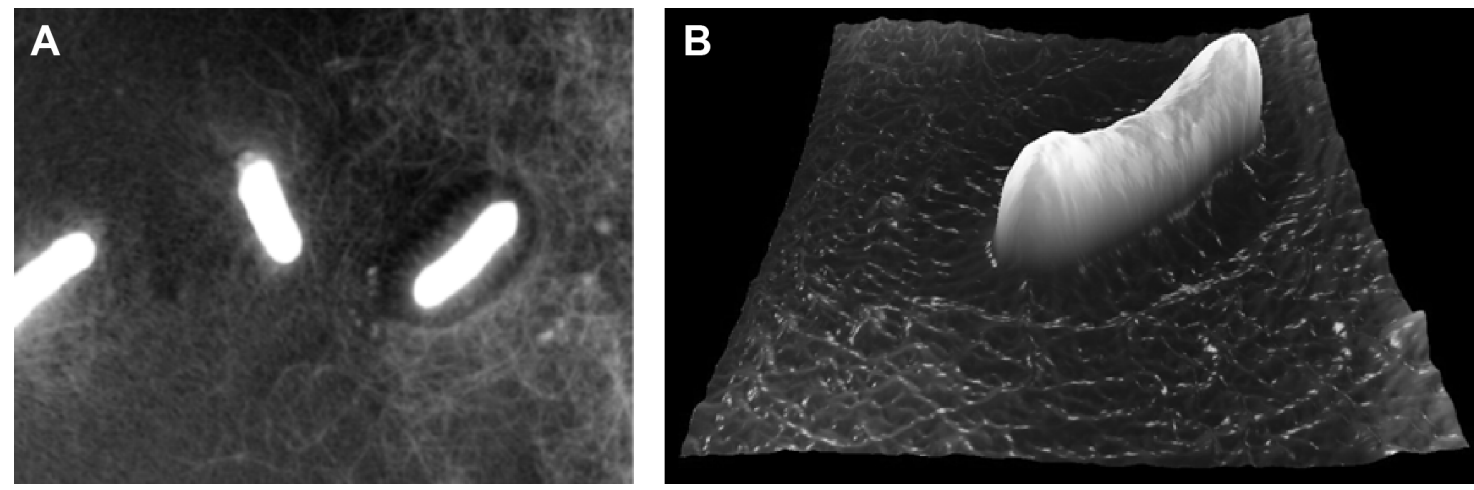

Figure 3 (A) AFM image (topography) of Bacillus bacterial infection on a gelatine substrate. (B) 3D reconstruction of a single Bacillus bacterium AFM image. Abbreviation: AFM, atomic force microscopy.

With nanomechanical biosensors, AFM cantilever, a real-time scanning of a live bacterial cell with high sensitivity was made possible. ${ }^{99}$ Furthermore, information on a cell's elasticity ${ }^{100}$ and the membrane-molecules' properties ${ }^{101}$ become available. The way by which bacteria adhere to tooth surfaces or dental implants has been revealed using AFM. This process usually starts with docking stage where nonspecific reversible attachments between bacteria and substrate through van der Waals and electrostatic forces exist. When the bacteria become close to the substrates, specific ligandreceptor interactions are formed, which is the locking stage. In this stage, molecules on bacterial surfaces and bacterial appendages such as fimbriae, pili, and capsules interact irreversibly with the substrate. ${ }^{102}$ This adhesion depends primarily on type and properties of both bacteria and the substrate as well as the surrounding environment. ${ }^{103}$ The formation of a biofilm usually starts with adhesion of initial colonizing species to the host surface; the coaggregation of late colonizing species, which change their phenotype and properties to adapt to the established biofilm, then follows. ${ }^{104,105} \mathrm{~A}$ biofilm is therefore a highly organized population of different adherent bacterial species embedded in a matrix of exopolysaccharides and proteins. ${ }^{106,107}$ The presence of different bacterial species in a biofilm increases its resistance to antibiotic and mechanical removal. ${ }^{108,109}$ Understanding how the bacterial cells adhere to different cell types ${ }^{110}$ and substrates at both nanoscale and picoscale levels, ${ }^{111}$ however, helps in understanding the biophysics of early phase or oral biofilm formation and pathogenesis of diseases. The adhesion of bacteria to tooth surfaces varies from species to species, eg, microbiomes have higher adhesion forces than planktonic bacteria. This could indicate the importance of early adhering bacteria for biofilm formation. ${ }^{12}$ AFM also provides precise information on biomechanical interactions of antibacterial drugs with a bacterial cell, ${ }^{113}$ for example, vancomycin binds to D-Ala-D-Ala terminal of peptidoglycan precursors of bacterial cell walls; $; 9$ this could help in the development of antibacterial therapies against drug-resistant bacteria.

\section{Imaging contrast enhancers and oral cancers}

One of the most prominent contributions from nanotechnology in the field of dentistry relates to the diagnosis of oral cancer lesions. The ability to image these lesions plays a critical role in overall cancer management and treatment plan design. Standard clinical imaging techniques, such as computer tomography (CT), molecular resonance imaging, and ultrasound, can be categorized as structural imaging techniques. As such, they are able to assist with the identification of anatomical patterns as well as the provision of basic information regarding tumor location, size, and spread based on endogenous contrast. However, in the case of tumors and metastases smaller than $5 \mathrm{~mm}$, these imaging techniques become less reliable to distinguish between benign and cancerous tumors. ${ }^{114,115}$ In 1895, Wilhelm Roentgen demonstrated serendipitously the use of gold as a contrast agent for X-ray imaging as he imaged one of his wife's (Anna Berha's) hands with a gold ring on her finger. Gold as an element exhibits a strong absorption of X-ray and can be used as a contrast agent in the form of gold nanoparticles (GNPs) for example.

GNPs can be synthesized using approaches such as the citrate reduction of aqueous $\mathrm{HAuCl}_{4}$ by the Turkevich method $^{116}$ and the Brust-Schiffrin two-phase synthesis method, which uses $\mathrm{NaBH}_{4}$ as a reducing agent and a mercapto-containing binding agent. ${ }^{117}$ The size distribution of the GNPs produced by both these approaches can be tuned by altering the chemical ratio of gold to reducing substance. 
Recent progress toward nanotechnology-based CT imaging has been made by Hainfeld et $\mathrm{l}^{118}$ following the wider accessibility of GNPs. Their original work focused on the use of GNPs to induce in vivo vascular contrast enhancement in CT imaging. In their preliminary work, ${ }^{119}$ the gold particles were not functionalized and consequently did not bind to any specific cell receptors. To increase the effectiveness and the specificity of the targeting of GNPs, it is essential to functionalize these particles. The functionalization of GNPs is usually accomplished either by direct thiol-modification of the targeting ligand or through the attachment of a targeting ligand to GNPs that have been modified with a coating material (eg, polymer, lipid, and DNA). The functionalization of GNPs with a ligand such as polyethylene glycol, for example, promotes both stability and persistence in circulation, allowing greater accumulation in the tumor tissue. It also provides a hydrophobic barrier to reticuloendothelial system phagocytosis and uptake. ${ }^{120}$ It is however still possible to increase the specificity of GNPs by functionalizing their surface with antibodies to markers overexpressed in tumors, such as EGF, HER2, and folate. ${ }^{121-123}$ In their approach, Marega et al have used a plasma-polymerized allylamine coating to enable the bioconjugation of tumor-targeting epidermal growth-factor receptor monoclonal antibodies to GNPs. ${ }^{121}$ Hainfeld et al produced HER2-targeted GNPs by coating $15 \mathrm{~nm}$ GNPs with polyethylene glycol and covalently coupling them to anti-HER2 antibodies. ${ }^{118}$ Popovtzer et al presented an in vitro proof of principle demonstration for head and neck cancer (oral squamous-cell carcinoma [OSCC]), ${ }^{114}$ showing that the attenuation coefficient for the molecularly targeted cells is over five times higher than for identical but untargeted cells. In their approach, the bioconjugation of the GNPs to the UM-A9 antibody was achieved according to the method described by Kim et al. ${ }^{124}$

Another contribution from nanotechnology arises in the detection of tumors using near-infrared (NIR) luminescent quantum dots (QDs). QDs are nanometer-scale semiconductor crystals composed of elements of groups II-VI or III-V and act as an inorganic fluorophore when exposed to an excitation wavelength. Metal and semiconductor nanoparticles in the size range of 2-6 $\mathrm{nm}$ are of considerable interest, due to their dimensional similarities with biological macromolecules (eg, nucleic acids and proteins). Similar to GNPs, QDs can be coupled to biomolecules, such as transferrin, ${ }^{125,126}$ immunoglobu$\operatorname{lin} \mathrm{G}$ (IgG), ${ }^{125}$ biotin, ${ }^{127}$ streptavidin, ${ }^{128,129}$ avidin, ${ }^{130,131}$ nucleic acids, ${ }^{132-134}$ peptides, ${ }^{135}$ serotonin, ${ }^{136}$ adenine, ${ }^{137}$ adenine monophosphate, ${ }^{137}$ and wheat germ agglutinin. ${ }^{126,137}$ These functionalized QDs effectively become luminescent probes that can bind with specificity and sensitivity to a variety of targets (immunoglobulin G, antigens, glycoproteins, nucleic acid sequences, and receptors). The luminescence of QDs is photostable with narrow, symmetric emission spectra and broad continuous excitation, allowing excitation of multiple QDs with a single wavelength. ${ }^{125-127,129,130}$ These properties make QDs very effective for labeling biological species in vivo. In 1998, Nie's and Alivisatos's groups independently reported the use of QDs for imaging of cells and tissues, and these studies have sparked the research growth of QD applications in life science. ${ }^{125,127}$

Head and neck squamous-cell carcinoma, also known as OSCC, is one of the most common types of cancer in oral oncology, representing $\sim 6 \%$ of all cases and accounting for an estimated 650,000 new cancers and $\sim 350,000$ cancer deaths globally per year. ${ }^{138,139}$ Selectively targeting of squamous tumors is a long-standing problem due to the lack of specificity of current drugs. In 2011, Yang et al ${ }^{140}$ successfully used cell-penetrating peptides to conjugate NIR QDs for cancer diagnostics. In their pioneering approach, they managed to label OSCC with QD conjugates by endocytosis for visual in vivo imaging on a mouse model. Working also on OSCC, Bhirde et al ${ }^{141}$ used a combination of QDs and CNT-based drug delivery to target and kill HN13 cells. Single wall carbon nanotubes (SWNTs) present remarkable opportunities to meet future advanced drug delivery system challenges. In a similar approach as described before, novel strategies are developed to bind biological molecules such as proteins and DNA and smaller molecules onto SWNTs. ${ }^{142-145}$ Functionalized, solubilized SWNTs can transport peptides, proteins, genes, and DNA ${ }^{146,147}$ across cell membranes with little cytotoxicity, ${ }^{148}$ making them an attractive carrier for both treatment and diagnosis strategies.

The use of QDs is not restricted to cancer diagnostics. This technology has also been used in the case of more common ailments such as dental caries and periodontal diseases where biofilms and bacterial infections play an important role. In 2003, Kloepfer et al were the first to use QDs for bacterial labeling. ${ }^{126}$ Since this pioneering work, the use of QDs has been more widespread and is now used for labeling, detection, and quantification of Mycobacterium bovis, Bacillus Calmette-Guérin, ${ }^{149}$ Escherichia coli O157:H7, ${ }^{150}$ and Salmonella enterica and serovar Typhimurium ${ }^{151}$ as well as for the simultaneous detection of E. coli O157:H7 and S. enterica and S. typhimurium. ${ }^{152}$ In 2007, Chalmers et al ${ }^{153}$ used QDs as luminescent probes to achieve single-cell resolution of oral bacteria biofilms. Using conjugated polyclonal and monoclonal antibodies bound to the QD surface, 
they were able to label planktonically grown Streptococcus gordonii DL1 cells as well as individual species within mixed-species community biofilms. Although this pioneering work is very promising, there is still a huge amount of work to be done to effectively target the correct species of bacteria for diagnostics purposes. The development of conjugation solution is currently the limiting factor for this approach to be more widespread, and current approaches are only limited to the laboratory rather than frontline patient diagnostics.

\section{Biochips and salivary biomarkers}

Possibly one of the most exciting uses of nanotechnology in oral health diagnostics comes from the emergence and development of biochips. ${ }^{154}$ Biochips are very small devices (less than a few millimeters) on which a collection of miniaturized test sites (microarrays) are arranged. The main advantage of the microchips over more traditional approaches is that many tests (diagnostics) can be performed simultaneously in order to achieve higher throughput and speed. Early work in this field related to dental diagnostics started in 2002 as the National Institute of Dental and Craniofacial Research in the USA initiated a concerted research effort in the area of saliva diagnostics. National Institute of Dental and Craniofacial Research funded several awards to develop microfluidics and microelectromechanical systems (MEMS) for saliva diagnostics with the aim to identify technologically viable systems and support their advancement toward commercialization. This unique venture focused on the development of microfluidic and MEMS technologies for measuring DNA, gene transcripts (mRNA), proteins, electrolytes, and small molecules in saliva, as well as overall profile correlates of a particular disease state, such as cardiovascular disease. ${ }^{155,156}$ One particular success came from Segal and Wong ${ }^{157}$ who found out that discriminatory and diagnostic human mRNAs are present in saliva of normal and diseased individuals. The salivary transcriptome presents an additional research and clinical resource, the second saliva-based diagnostic alphabet for disease detection. This work led to the development of salivary diagnostic technology using MEMS and nanoelectromechanical system biosensors. These devices exhibit exquisite sensitivity and specificity for analyte detection, down to single-molecule level. ${ }^{158,159}$ Subsequently, the research consortium led by Wong developed the oral fluid nanosensor test. ${ }^{157,160-162}$ This handheld, automated, easyto-use, integrated system enables simultaneous and rapid detection of multiple salivary protein and nucleic acid targets. In 2007, Gau and Wong suggested that the intended use of the oral fluid nanosensor test is for point-of-care multiplex detection of salivary biomarkers for oral cancer. ${ }^{160}$ In their work, they demonstrated that the combination of two salivary proteomic biomarkers (thioredoxin and interleukin-8 [IL-8]) and four salivary mRNA biomarkers (SAT, ODZ, IL-8, and interleukin-1 beta [IL-1 $\beta]$ ) can detect oral cancer with high specificity and sensitivity.

Another important emerging tool in oral health diagnostics involves profiling methods that are available for detecting miRNA expression levels and were recently reviewed by Yoshizawa and Wong. ${ }^{161}$ miRNAs are short noncoding RNA molecules that play important roles in regulating a variety of cellular processes. Dysregulation of miRNAs is known to be associated with many diseases, such as OSCC. The presence of miRNAs in saliva and their potential as non-invasive biomarkers in oral cancer detection was shown to be an effective marker in the case of OSCC using miR-31 over-expression. ${ }^{163}$ The profiling methods involve biochemical techniques, such as quantitative PCR, ${ }^{164,165}$ microarray hybridization, ${ }^{166,167}$ and next-generation sequencing. The miRNAs present in saliva are very low, typically in the nanogram range upon extraction. The challenge of these profiling methods is thus to be able to quantify very low quantities of the miRNAs present in saliva, which is typically in the nanogram range upon extraction. An example of such profiling techniques is Applied Biosystems Stem-loop RT based TaqMan ${ }^{\circledR}$ MicroRNA Assay. This method measures quantitation for mature miRNA expression and is believed to be the goldstandard method with a large dynamic range, high specificity, and high sensitivity. ${ }^{164,168,169}$

Another venture in the field of biochips comes from the work initiated by Weigum et al on the development of a diagnostic cytology-on-a-chip technique that rapidly detects premalignant and malignant cells with high sensitivity and specificity. ${ }^{170,171}$ In their approach, they designed a sensor for the diagnostics of OSCC, which integrates multiple laboratory processes onto a microfluidic platform in three primary steps. First, an oral-cytology suspension is delivered to the sensor using pressure-driven flow, where any cells larger than the membrane-pore size are retained on the membrane surface. ${ }^{170,171}$ The captured cells are then stained with fluorescent dyes and immunoreagents to distinguish the cytoplasm, nucleus, and cancer biomarkers. In their diagnostic approach, they selected epidermal growth-factor receptor as the targeted biomarker, since it is overexpressed and well characterized in OSCC and associated with aggressive phenotypes. Finally, the stained cells are subjected to a 3D fluorescence-microscopy scan of the membrane surface. This is followed by automated image analysis using open-source 
software. The advantage of this approach is the speed at which a diagnosis can be made.

In the field of periodontal diseases, ${ }^{162}$ Christodoulides et al have developed an electronic microchip-assay to detect C-reactive protein (CRP), which is a biomarker for inflammation associated with periodontal disease at the picogram per milliliter level. ${ }^{172} \mathrm{CRP}$ is known to be a systemic marker produced as a response to inflammatory stimuli ${ }^{173}$ that can be used to differentiate in serum, between a healthy state and the presence of periodontitis ${ }^{174,175}$ and saliva. ${ }^{176}$ It is the ability of the biochip to detect very low concentrations of CRP present in the saliva compared to serum that has enabled the researchers to distinguish between healthy periodontium and chronic gingival inflammation based directly on salivary CRP levels. ${ }^{177}$ Moreover, CRP is also classified as a systemic marker of inflammation that has been shown to significantly increase in other conditions, including myocardial infarction, atherosclerosis, and arthritis. ${ }^{178-180}$ Another device called the integrated microfluidic platform for oral diagnostics was developed to perform immunological assays in less than 10 minutes with low sample volume and concentration requirements to test for periodontal disease. ${ }^{181}$ This device is able to detect proteins in the picomolar range for tumor necrosis factor- $\alpha$ (TNF- $\alpha$ ) and interleukin-6 (IL-6) that have been spiked into saliva. IL- 6 is released in response to IL-1 and TNF and has been shown to increase proportionally with bone loss in adult chronic periodontitis patients. ${ }^{182}$ The proinflammatory and immune regulatory cytokine, TNF- $\alpha$, has been identified in saliva and is significantly elevated in people with periodontitis compared with healthy individuals, with increased levels being correlated with increased numbers of sites with bleeding upon probing, pocket depth, and higher clinical attachment levels. ${ }^{183,184}$

\section{Toward clinical trials}

It is clear that there is an effort by the scientific communities to develop new tools to diagnose dental ailments more locally, more precisely, and with a lesser amount of analytes. However, it is also evident that the current level of research undertaken has not yet yielded methods or devices that can be used in a widespread manner for clinical trials. There is a clear lack of clinical trials associated with any nanotechnologybased diagnostic approaches in the current literature. Most of the current nanoscale diagnostic approaches applied to dentistry evolve from the vast number of strategies currently used in medicine, as was seen for cancer. There are a number of isolated clinical cases or reports suggesting that the field of dentistry is slowly appreciating the merits of these approaches. Dentistry is traditionally a very conservative discipline, and this may explain the reason for the current reticence to use these novel approaches. Nanotechnology is yet to find a diagnostics solution for common ailments, such as dental decay and erosion, and has only started to find a solution in the field of periodontology. Until nanotechnology can bring more advanced methods to diagnose or prognose such common conditions, nanotechnology's impact may be limited in terms of a diagnostic tool in the field of dentistry.

\section{Therapeutic nanodentistry}

The use of nanotechnology in treating dental diseases has found a great interest. Its use has been extended from treating dentin hypersensitivity, root canal disinfection, and oral cancer to the most recent use in tissue engineering and drug delivery applications.

\section{Dentin hypersensitivity}

Dentin is protected from external stimuli by enamel in the crown or by cementum in the root. The removal of this protective layer exposes the underlying dentinal tubules, changing the fluid pressure hydrodynamics of the fluid inside the dentinal tubules, and is believed to be responsible for dentin hypersensitivity. GNPs were found to be easily adsorbed on the inner dentinal tubule walls; the application of silver staining was then used to help to occlude the open tubules and reduce the dentin sensitivity. After brushing the opened tubules with highly concentrated GNPs, laser irradiation promoted the aggregation of nanoparticles to occlude the exposed tubules. ${ }^{185}$ Furthermore, dental nanorobots offer a quick and permanent cure to dentin hypersensitivity by selectively and precisely occluding the tubules in minutes using biological materials. ${ }^{186}$

\section{Root canal disinfection}

Several nanoparticles, such as zinc oxide and chitosan alone or in combination, have been incorporated into root canal sealers in an attempt to disinfect root canals. They had no effect on the flow characteristic of the sealers, but they enhanced the antibacterial action, observed by a significant reduction in Enterococcus faecalis adherent to treated dentin. ${ }^{187}$ Prior surface treatment of root canal dentin with phosphorylated chitosan was effective in maintaining the inhibitory effect of a chitosan-modified root canal sealer on biofilm formation at the sealer-dentin interface. ${ }^{75}$ Metal oxides such as magnesium oxide nanoparticles could be used as a potential root canal irrigant with promising antibacterial activity in both in vitro and ex vivo studies. Compared 
to the conventional $\mathrm{NaOCl}$ solution $(5.25 \%)$, magnesium oxide nanoparticles ( $5 \mathrm{mg} / \mathrm{L})$ showed statistically significant long-term effect in the elimination of $E$. faecalis adherent to root canal dentin. ${ }^{188}$

\section{Oral cancers}

In cancer radiation therapy, GNPs were conceived as a radiosensitizer and they caused cell death after gamma radiation. The radiosensitivity of GNPs is dependent on their sizes. ${ }^{189}$ In cancer chemotherapy, nanodelivery vehicles (eg, naringeninloaded nanoparticles in 7,12-dimethylbenz(a)anthracene) ${ }^{190}$ were used for improving the stability as well as targeted and controlled delivery of chemotherapeutic drugs. In photothermal therapy, this relies on the use of a plasmonic probe and NIR light, recently introduced as a minimally invasive technique for the treatment of deep tissue malignancy such as OSCC. ${ }^{91}$ In this therapy, GNPs, with their enhanced NIR absorbance and ability to convert the absorbed light into heat energy, were used as a plasmonic nanoprobe. The nanodimension of this probe ensures its easy absorption by the localized tissue, reduces its toxicity, and allows its removal from the body after the treatment. Further enhancement of their biocompatibility, coating the gold nanostructures with thermo and $\mathrm{pH}$-responsive polymers, for example poly(Nisopropylacrylamide-co-acrylic acid), has been attempted. RGD (arginine-glycine-aspartate) and NLS (nuclear localization sequence) peptides-conjugated nuclear targeting gold nanostructures can be easily captured by cancerous cells (eg, OSCC), subsequently disturb their functions (DNA damage, induces cytokinesis arrest in cancer cells) inducing cell apoptosis and necrosis. ${ }^{191}$ The composition and shape of these nanostructures (eg, nanorods, ${ }^{91}$ nanospheres, and nanocages ${ }^{192}$ ) would further enhance their apoptotic activity. In addition to disruption of cellular functions, gold nanocages produced reactive oxygen species that also kill the cancerous cells. ${ }^{191}$ Selective inhibition of cancer cell growth through mitochondria-mediated autophagy has been obtained by iron-core-gold shell nanoparticles. ${ }^{193}$

In addition to treating cancer, nanotechnology has been also extended to offer an effective management of the breakthrough pain associated with cancer. A nanodelivery transbuccal system was developed to rapidly and efficiently deliver the opioid analgesia at a consistent and controlled diffusion into the target tissue. Accordingly, it minimizes the risk of overdosing in patients and also protects the patients from needle injection. It also avoids the enzymatic and spontaneous degradation of the drug associated with oral administration. ${ }^{194}$

\section{Tissue engineering}

Tissue engineering in dentistry, like other medical areas, has been approached to combine the technologies of scaffold matrices with the regenerative power of stem cells, which can be sourced mainly from dental tissues such as dental pulp, periodontal ligament (PDL), and alveolar bone. ${ }^{195}$ The scaffolding matrices need to have specific functionality, such as to provide surfaces that allow cell attachment, proliferation, and differentiation as well as to present porous networks that enable the penetration of cells and nutrients. ${ }^{196}$ Furthermore, the matrices need to degrade at an appropriate rate to meet the regeneration speed of tissues while preserving a certain level of mechanical integrity. ${ }^{196}$

Nanotechnology in tissue engineering has allowed significant improvement of these scaffolding materials to present unique 3D matrix conditions for cells and tissues. ${ }^{197,198}$ Nanoengineered scaffolds possess intrinsic mechanical properties of materials that cannot be readily achieved by conventional technologies. The nanotopological surfaces provide more definitive physicochemical cues to cells that can recognize the nanoscale structures in their adhesion and differentiation. Furthermore, many biological proteins and active molecules can be integrated with the scaffolding materials at the nanoscale level to exert therapeutic efficacy and to spatially control the cellular behavior. Therefore, the nanotechnology-driven tissue engineering can achieve native tissue mimicking architectures and/or evoke the phenomena that occur in nature, ultimately to create constructs that are equivalent to tissues in dentistry, including dentin, pulp, PDL, cementum, and alveolar bone.

Some examples in biology highlight the hierarchical organization of tissues at the nanoscale, which ultimately informs insights into the design rationale for scaffolding matrices by nanotechnology. For instance, the ECM of many connective tissues is composed of collagen fibers that are formed through self-assembling of smaller subunits. The collagen molecules with a triple helical structure assemble once they are secreted into the extracellular space, forming collagen fibrils, which in turn form collagen fibers that range in sizes between $50 \mathrm{~nm}$ and $500 \mathrm{~nm}$. In bone, the collagen self-assembled fibrils/fibers can template the mineralization of HA nanocrystals in a highly ordered manner. To engineer this hierarchical nanocomposite bone structure, a lot of effort has been exerted. The self-assembling peptides could be designed to mimic this, through modifying the amino acid sequences that could act as nucleating sites of the mineral phase. ${ }^{199,200}$ The process can also control the crystallographic orientation of the HA, which aligns along the $c$-axes with 
the long axes of the organic fibers, similar to that found in bone. ${ }^{199}$

Such a bottom-up approach to create native tissue architecture can provide an engineered construct with unique mechanical properties. In fact, enamel in the teeth is believed to form through the mineralization of an amelogenin-based matrix protein, allowing the precipitation of nanometric crystals with perfect organization that ultimately confers hard and strong mechanical functions placed in tooth surface. ${ }^{201}$ Furthermore, the unique mechanical properties of dentin can also be created by the HA mineralization in the dentin matrix proteins, which feature the assembly of acidic clusters into beta-sheet for hierarchically oriented mineral formation. ${ }^{202}$ Therefore, exploiting the nanoarchitecture of the native dental tissues has often been a topic of research in dental tissue engineering scaffolds. The electrospun nanofibers, ${ }^{203-205}$ selfassembling peptides, ${ }^{206,207}$ and phase-separation matrices ${ }^{208,209}$ are the representative cases.

The nanofibrous scaffolds have been widely developed as the matrices for regeneration of dental tissues, including dentin-pulp complex, enamel, PDL, cementum, alveolar bone, and temporomandibular joint. A key aspect of the nanofibrous structures is their morphological trait largely mimicking the native tissue architecture because most of tissue proteins such as collagen and elastin are nanofibrous. Owing to their large surface area relative to volume, the surface-related properties are dominant, and these include surface reactivity, protein adsorption, and surface degradation, which ultimately control the cellular behaviors. ${ }^{210,211}$

Dentin and pulp are one of the most widely explored dental tissues utilizing the nanofibrous scaffolds. Nanofibrous scaffolds can be produced either by phase-separation, electrospinning, or peptide synthesis approach. For example, nanofibrous scaffolds made of poly-l-lactide acid (PLLA) could be synthesized through phase-separation and porogen leaching methods. The scaffolds exhibited the stimulation of odontogenic differentiation in human dental pulp stem cells when compared to solid-walled PLLA scaffolds. ${ }^{208,209}$ Furthermore, when ectopically implanted for 8 weeks in nude mice, the nanofibrous matrix provided excellent $3 \mathrm{D}$ environments for dental pulp stem cells to regenerate dental pulp as well as dentin. ${ }^{208}$

Electrospinning is a more common method to generate nanofibers. Some recent studies have developed nanocomposite nanofibrous scaffolds made of biopolymers with bioactive glass, where the bioactive glass role was to provide high bioactivity. ${ }^{204,212}$ The dental pulp stem cells showed improved proliferation, differentiation, and mineralization on the nanofibers containing bioactive glass when compared to the pure polymer nanofibers. ${ }^{204,212}$ When combined with nanohydroxyapatite, the electrospun biopolymer nanofibers were also demonstrated to have improved proliferation and odontogenic differentiation of dental pulp stem cells. ${ }^{205,213,214}$ These studies implicated the importance of bioactive inorganic nanoparticles that possibly play significant roles in improving mineralization and remineralization of dentin matrices that are damaged and diseased. ${ }^{215}$ An interesting study reported nanofibrous scaffolds that incorporate magnesium phosphate, where the magnesium ions were shown to be sustainably released and to play a role in enhancing the differentiation of dental pulp stem cells. ${ }^{216}$ Furthermore, when these stem cell-cultured scaffolds were ectopically implanted in nude mice, a greater level of ECM deposition, hard tissue formation, and expression of marker proteins could be achieved when compared to the Mg-free scaffolds, showing the importance of ions in odontogenesis. ${ }^{216}$

Peptide self-assembly is an intriguing method that enables a bottom-up approach to generate nanofibers. As a representative example for dentin-pulp regeneration, the RGD sequence was designed in the peptide nanofiber scaffolds to control dental pulp cellular behaviors. The dental pulp stem cells were shown to express odontoblast-like phenotypes, and the deposition of mineral was possible. ${ }^{217}$ Another study to mimic the native dentin structure used a methacrylate-based matrix with interpenetrated silica nanophase, which enabled aligned pores in the micrometer range. The matrices were shown to form a neodentinal cellular pattern distribution once implanted subcutaneously in mice. ${ }^{218}$ These matrices with nanofibrous structures can be potential scaffolding platforms in the stimulation of dental pulp stem cells and ultimately in the engineering of dentin-pulp complex tissues.

The nanofibrous matrix has also been developed to mimic the enamel. Enamel consists mainly of crystalline HA and is the external layer of tooth; therefore, its erosion or a caries attack may affect the dentin hypersensitivity. A couple of approaches have been proposed using nanomaterials to regenerate enamel. One exemplar study used electrospun polymer nanofibers containing amorphous $\mathrm{CaP}$. In the presence of $\mathrm{F}$ ions, the amorphous CaP was able to transform into a contiguous overlayer of crystalline fluoridated apatite of $500 \mathrm{~nm}$ in thickness (Figure 4A-C). ${ }^{219}$ Another interesting approach was based on self-assembling peptides, which contain high amounts of Arg-Gly-Asp (RGD) sequences. The unique structure allowed the ability to induce proliferation and differentiation of ameloblasts, which were able to synthesize, organize, and biomineralize enamel nodules (Figure 4D and E). However, compared to other tissues like dentin, the regeneration of enamel structures remains a significant challenge 

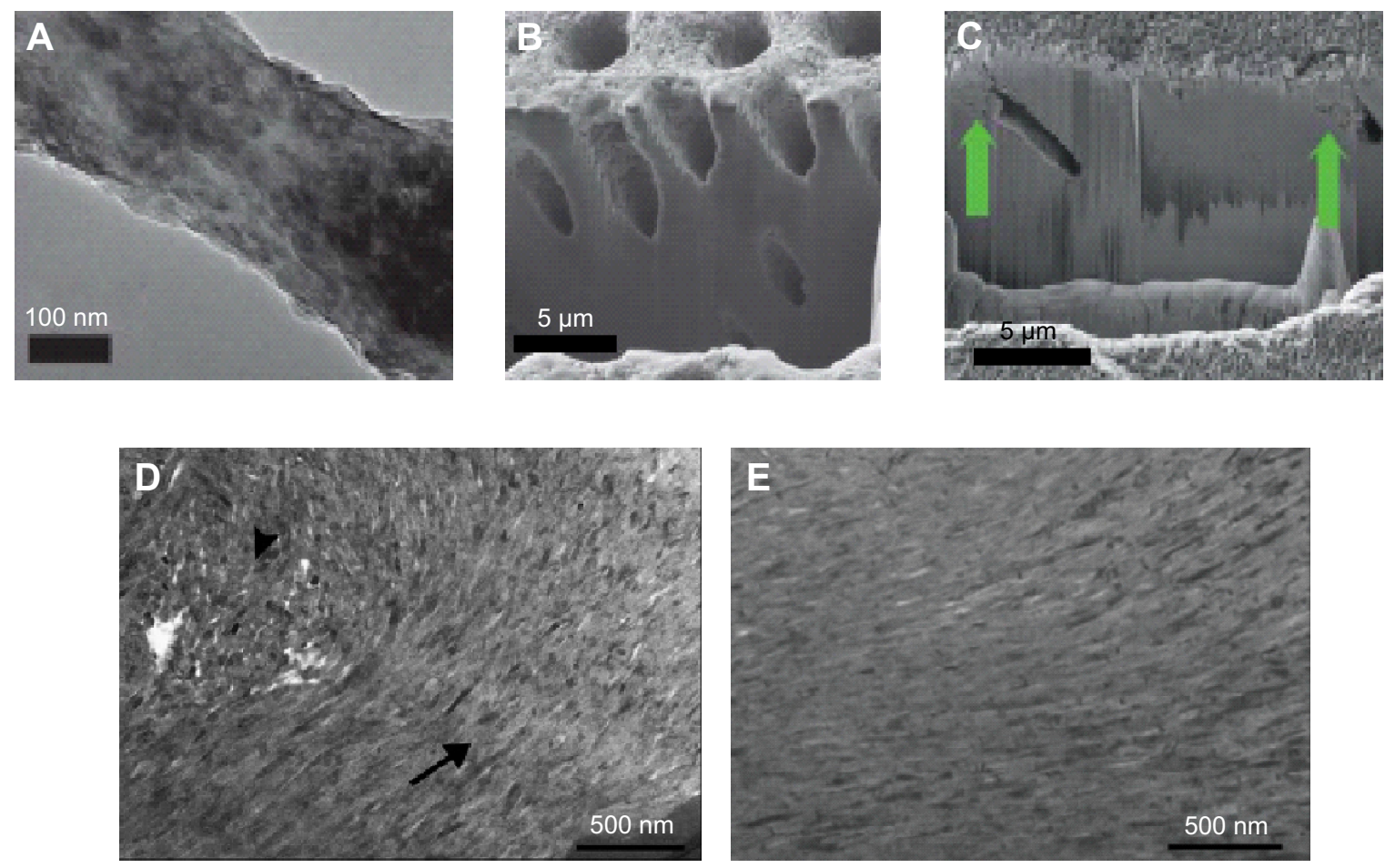

$\mathbf{F}$

\section{RADA16}

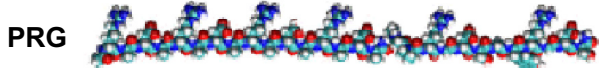

Self-assembling motif Functional motif

G
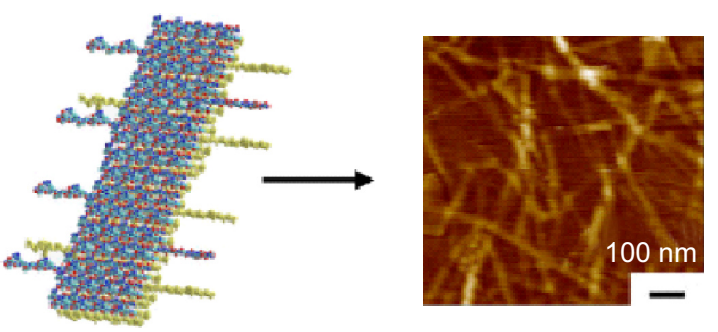

H
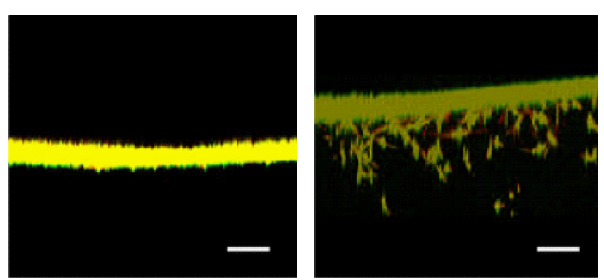

Figure 4 Ability of electrospun nanofibers containing ACP to regenerate dentin structure, as revealed by TEM image (A). Dentin cross-section imaged after etching (B) and after treatment with hydrated ACP/PVP (C), showing occlusion of tubules (green arrows). Regeneration of enamel by self-assembling peptides, showing aligned HA crystals sectioned longitudinally (arrows) and in cross-section (arrowheads) (D), representing considerable resemblance to that of authentic enamel (E). Molecular models of designed peptides RADAI6 and PRG (F) and the formation of the self-assembled nanofiber present a beta-sheet structure (G). Periodontal ligament fibroblasts cultured in collagen gel in the presence or absence of the functional peptide, showing the ability of cells to penetrate into the gel when the PRG sequences were present in the gel $(\mathbf{H})$. (A-C) Adapted from Fletcher J, Dominic W, Emma Fowler C, Mann S. Electrospun mats of PVP/ACP nanofibres for remineralization of enamel tooth surfaces. Cryst Eng Comm. 201 I; 13:3692 with permission of The Royal Society of Chemistry. ${ }^{219}$ (D and E) Adapted from Biomaterials, 3I, Huang Z, Newcomb CJ, Bringas P Jr, Stupp SI, Snead ML, Biological synthesis of tooth enamel instructed by an artificial matrix, 9202-921 I, Copyright @) 2010, with permission from Elsevier. ${ }^{206}$ (F-H) Adapted from Kumada Y, Zhang S. Significant type I and type III collagen production from human periodontal ligament fibroblasts in 3D peptide scaffolds without extra growth factors. PLoS One. 2010;5:el 0305. ${ }^{207}$

Abbreviations: ACP, amorphous calcium phosphate; TEM, transmission electron microscopy; PVP, poly(vinylpyrrolidone); HA, hydroxyapatite. 
as the erupted enamel is principally acellular, and thus, the involvement of progenitor/stem cells can be considered mainly at the early stage of tooth development. ${ }^{206}$

The periodontal pockets, including PDL, cementum, and alveolar bone, have also been in great need of nanostructured scaffolds for engineering. The electrospun nanofibers of poly(lactic-co-glycolic acid) (PLGA) or gelatin were used to culture human PDL cells, showing the ability to adhere, proliferate, and osteogenically differentiate. ${ }^{203,220}$ The incorporation of silica or HA nanoparticles on the surface of these nanofibers has been shown to enhance protein adsorption, which resulted in improved adhesion of PDL fibroblast cells. ${ }^{221}$ When the scaffolds contained nanosized HA, protein adsorption, cell adhesion, and in vivo bone formation were significantly higher than scaffolds containing conventional HA. ${ }^{222}$ When PDL stem cells were seeded on the engineered nanosurface, cell viability and differentiation were enhanced compared to the absence of the nanosized HAs. The silk scaffolds were also tailored with nanohydroxyapatite to have mineralized surface. ${ }^{223}$ The scaffolds constructed with PDL stem cells demonstrated substantial level of periodontal regeneration in an in vivo implantation in dogs, suggesting a potential scaffolding matrix for periodontal tissue engineering. ${ }^{223}$ In a similar way, the nanosized bioactive glass particles were incorporated into alginate scaffolds, which showed enhanced proliferation and differentiation of human PDL fibroblasts when compared to the alginate-only scaffolds. ${ }^{224}$ Other than the electrospun nanofibers, the self-assembling peptides containing the RGD-binding sequences (PRG) and laminin cell adhesion motif (PDS) were designed, which demonstrated significant promotion of PDL fibroblast adhesion, proliferation, and protein production (Figure $4 \mathrm{~F}-\mathrm{H}$ ). ${ }^{207}$

Alveolar bone defects have also been regenerated with nanometric-engineered scaffolds. The nanohydroxyapatite/ polyamide nanocomposite scaffolds produced by a phaseseparation method were combined with bone marrow stromal cells and then implanted into rabbit jaw bone. The results showed the enhancement of osteogenic markers in the implanted samples with cells, showing the ability of these scaffolds to stimulate osteogenesis, although the amount of new bone formed was not enhanced in the presence of the cells. ${ }^{225}$ Similar results were obtained using nanosized $\beta$-tricalcium phosphate within a collagen matrix, which showed enhanced bone regeneration when implanted with MSCs. ${ }^{226}$

\section{Drug delivery}

The delivery of therapeutically relevant molecules is a promising approach to improve the regeneration ability of damaged tissues and to treat diseases effectively. These molecules are usually loaded in carriers, such as scaffolds or nanoparticles, to allow controlled and sustained release, ultimately influencing a series of biological processes, such as cell homing, attachment, proliferation, and differentiation. The therapeutic molecules should be safely loaded in large quantities and then delivered in a controlled and targeted manner.

Therefore, the design of delivery carriers is of special importance in the success of the delivery systems. When $3 \mathrm{D}$ scaffolds are the carriers of the molecules to deliver, the signaling molecules can be combined within the 3D structure or on the surface of the scaffolds. As a result, the therapeutic molecules are released to the surrounding tissues and then act to regulate cellular functions. They can also be used as the tissue engineering matrices in the cultivation and differentiation of stem cells. In these cases, the incorporation of the signaling molecules should be carefully considered on the basis of nanochemistry of scaffolds, for example, molecular bonding between scaffold networks and drug molecules. On the other hand, nanosized particles are the most common form of delivery carriers because the carriers are often intended to enter the cell membrane and sometimes even to the nucleus. ${ }^{227,228}$ Together with many different nanoparticulates made of either polymers or inorganics, their hybrids have been developed for the delivery of molecules. Those targeted for dental tissues are relatively less explored.

Among the target areas that need a delivery strategy of signaling molecules, periodontal disease is a common problematic issue in dentistry. ${ }^{229}$ The periodontal disease is primarily due to the bacterial infection that can possibly destroy the host tissues and eventually lead to tooth loosening. The treatment for periodontal diseases is based on two main approaches: the elimination of bacteria to avoid the progression of the disease and the regenerative therapy that may allow the regeneration of the damaged tissue. ${ }^{230}$ To this end, BMPs have been often used since they are involved in the osteogenic differentiation of stem cells showing the ability to regenerate PDL, cementum, as well as alveolar bone when administered from biomaterials. ${ }^{231-234}$ In a similar way, when dental pulp is infected, a common clinical treatment involves bacterial control and removal of whole pulpal tissues. Therefore, the successful regeneration of odontoblasts, endothelial cells, fibroblasts, and even neurons is greatly needed to restore pulp tissue. Owing to the complexity of the cells involved in the regeneration process, many different growth factors, such as transforming growth factor (TGF- $\beta 1$ ), BMP, and platelet-derived growth factor can be 
used individually or in combination. The presence of dental caries requires ultimately the regenerative signals of both enamel and dentin, for which antibacterial drugs play a key role at the initial phase. Furthermore, for the regeneration of the temporomandibular joint, delivering molecules to target two different tissues (cartilage and bone) is required; thus, the use of dual factors such as BMP 2 and TGF- $\beta$ may be an appropriate delivery option.

Utilizing nanoparticles to deliver therapeutic molecules has been explored for periodontal regeneration. The most common molecular type is the small drug that can be antibacterial in periodontal diseases. PLGA nanoparticles were developed to encapsulate minocycline for periodontal infections. The nanoparticles of size 85-424 nm have an entrapping efficiency of up to $29.9 \% .{ }^{235}$ The release was shown to be sustained for several weeks, which resulted in a considerable antibacterial effect compared to the minocycline-free nanoparticles. ${ }^{235}$ Similar nanoparticles composed of PLGA and poly(lactic acid) showed higher entrapment efficiencies of up to $63.8 \%$, and their implantation in dogs showed that the nanoparticles loaded with triclosan were able to penetrate through the junction epithelium. ${ }^{221,236}$ A more osteoconductive vehicle for the delivery of tetracycline was developed using calcium-deficient $\mathrm{HA}$ nanoparticles with varying $\mathrm{Ca} / \mathrm{P}$ ratios. ${ }^{237}$ The loaded drug showed sustained release of up to $88 \%$ over a period of 5 days and considerable antibacterial effect. Furthermore, when the drug-loaded nanoparticles were placed in contact with PDL cells, the cell proliferation increased, suggesting that the use of HA nanoparticles as local drug delivery agents in periodontal treatment may be a good option. ${ }^{237}$

Growth factors have also been used for their therapeutic action in dental tissues. Compared to the common drug molecules, growth factors require water-based solutions in the nanoparticle processing. Some of the examples are illustrated in Figure 5. For this purpose, glycydil methacrylate, derivative dextran, and gelatin nanoparticles were prepared with a size of $53.7 \mathrm{~nm}$ to encapsulate BMP, which showed a sustained release of more than 12 days. Furthermore, the nanoparticles were shown to be biocompatible and could be used as a promising vehicle for the delivery of active molecules to the periodontium. ${ }^{238}$ Nanodiamonds, which are carbon nanoparticles of 4-5 nm, have also been used as a growth-factor carrier for the alveolar ridge augmentation. These have been shown to effectively physisorb and simultaneously deliver BMP2 and fibroblast growth factor and are able to induce the differentiation and proliferation of osteoblasts (Figure 5A and B). ${ }^{236}$
Owing to some concerns related to the lack of continuous supply of growth factors, gene therapy has been proposed as a possible solution. ${ }^{239}$ For the delivery of genetic molecules, the carriers should be positively charged to enable complexes with highly phosphorylated nucleic acids. Nanosized $\mathrm{CaP}$ particles were developed with $30-50 \mathrm{~nm}$ in size to load the platelet-derived growth factor gene. Results showed significantly higher PDL fibroblast proliferation when placed in contact with the gene-complexed nanoparticles. ${ }^{239}$ In a similar way, BMP2 gene was loaded onto $\mathrm{CaP}$ nanoparticles. Dental pulp stem cells were able to uptake the complex particles and then express considerable levels of odontogenic differentiation. ${ }^{240}$ Alveolar bone regeneration has also been achieved through the delivery of polymeric nanoparticles that carry siRNA molecules for the interference of Sema4d, which is considered as a target gene for osteoporosis. The results showed, after injection in mice, that the siRNAloaded nanoparticles were able to increase significantly the formation of bone in the osteoporotic alveolar bone (Figure 5C and D). ${ }^{241}$

These nanoparticles are often incorporated into the 3D matrices to allow scaffolding roles while maintaining the controlled and sustained release of the encapsulated molecules. Some examples are illustrated schematically in Figure 6. For instance, tetracycline-loaded nanoparticles of size around $130 \mathrm{~nm}$ were prepared using an ionic gelation method, which was then incorporated in a calcium sulfate cement matrix. ${ }^{242}$ The release pattern was sustained and presented an antibacterial effect as well as an enhanced ALP activity of human PDL cells. ${ }^{242}$ In a similar way, chitosan loaded with tetracycline was prepared as nanoparticles by a solution nebulization method, which was then incorporated into polycaprolactone (PCL) nanofibers. The release pattern of the drug from naked nanoparticles actually showed a burst with $\sim 70 \%$ of release initially, which, however, was sustained significantly when incorporated within the PCL nanofiber structure. ${ }^{243}$ For the regeneration of mandible defects, the nanohydroxyapatite/collagen scaffolds were developed to deliver BMP2-derived peptides. The nanocomposite scaffolds showed sustained and controlled release of the peptide molecules as well as enhanced osteogenic capacity of marrow stromal cells. ${ }^{244}$ Nanocomposite scaffolds of HA nanoparticles with PCL were also reported to deliver BMP2 and have an excellent ability to regenerate the mandibular bone defect in rabbits (Figure 6A-C). ${ }^{245}$ The BMP2-loaded nanohydroxyapatite/collagen/poly(lactic acid) constructs also showed a slow release of BMP2, which resulted in high osteogenic signaling of dental pulp stem cells. Furthermore, 

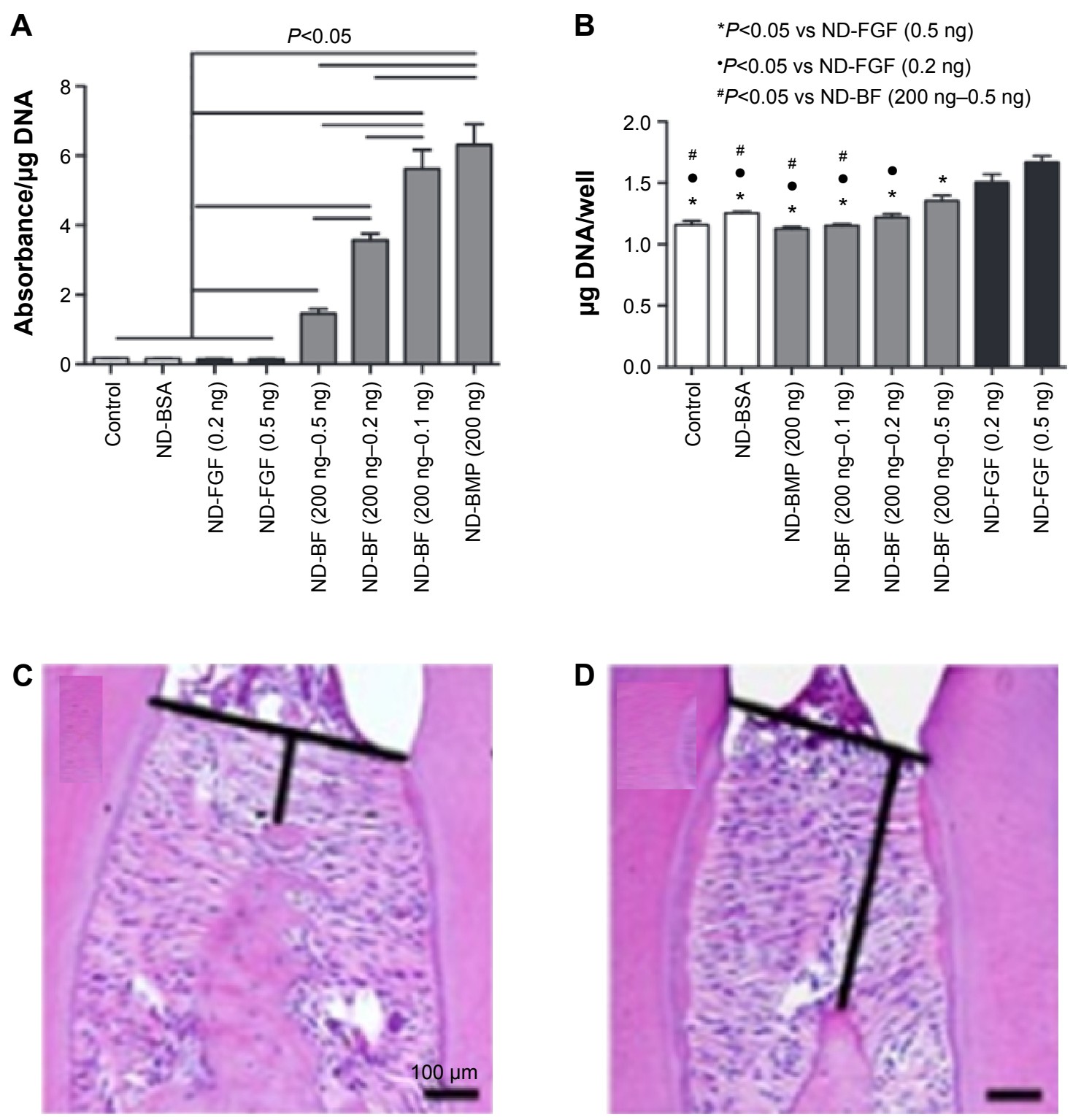

Figure 5 (A, B) Effects of BMP2 and FGF delivered by nanodiamonds on osteoblast differentiation and proliferation. ALP activity at 5 days was inhibited by the use of FGF with the nanodiamonds (ND-FGF), but was considerably increased in a dose-dependent manner when the ND-FGF were combined with BMP2 (ND-BF) or when the BMP2 was administered alone (ND-BMP) (A). Osteoblast proliferation shows that BMP did not enhance proliferation (ND-BMP), whereas the presence of FGF alone (ND-FGF) or in combination with BMP significantly enhanced proliferation (ND-BF) (B). (C, D) Mandibular bone loss decreased by siRNA delivery. Histological observation of the mandibular inter-molar alveolar bone height loss significantly decreased in the presence of Sema4d-siRNA-loaded nanoparticles (C) compared to control (D). (A and B) Moore L, Gatica M, Kim H, Osawa E, Ho D, Journal of Dental Research, (92), 976-987. Copyright (C) 2013 by International \& American Associations for Dental Research. Adapted by permission of SAGE Publications. ${ }^{236}$ (C and D) Zhang Y, Wei L, Miron RJ, Zhang Q, Bian Z, Journal of Dental Research, (93), I095-II00. Copyright (C) 20I4 by International \& American Associations for Dental Research. Adapted by permission of SAGE Publications. ${ }^{241}$

Abbreviations: BMP, bone morphogenetic protein; FGF, fibroblast growth factor.

when the BMP2-loaded scaffolds in combination with dental pulp stem cells were implanted in rabbits, the bone formation was similar to that of autologous bone, proving that BMP2 was able to promote higher differentiation of the loaded stem cells, which in turn enhanced bone regeneration. ${ }^{246}$

Nanofibers have often been shown to be excellent matrices for the sustained delivery of drugs mainly due to their high surface area. For PDL regeneration, nanofibers composed of PCL effectively encapsulated metronidazole benzoate and presented a low burst and sustained release of the drug up to 19 days. ${ }^{247}$ Similarly, doxycycline was encapsulated into PLGA nanospheres, which were then incorporated into PLLA nanofibrous scaffolds. ${ }^{248}$ The drug release was strongly dependent on the physical and chemical composition of the nanospheres, showing a complete release up to 6 weeks and a strong antibacterial effect (Figure 6D) ${ }^{248}$ Nanofibers have also been used for the treatment of pulp infections, using polydioxanone incorporating metronidazole or ciprofloxacin 

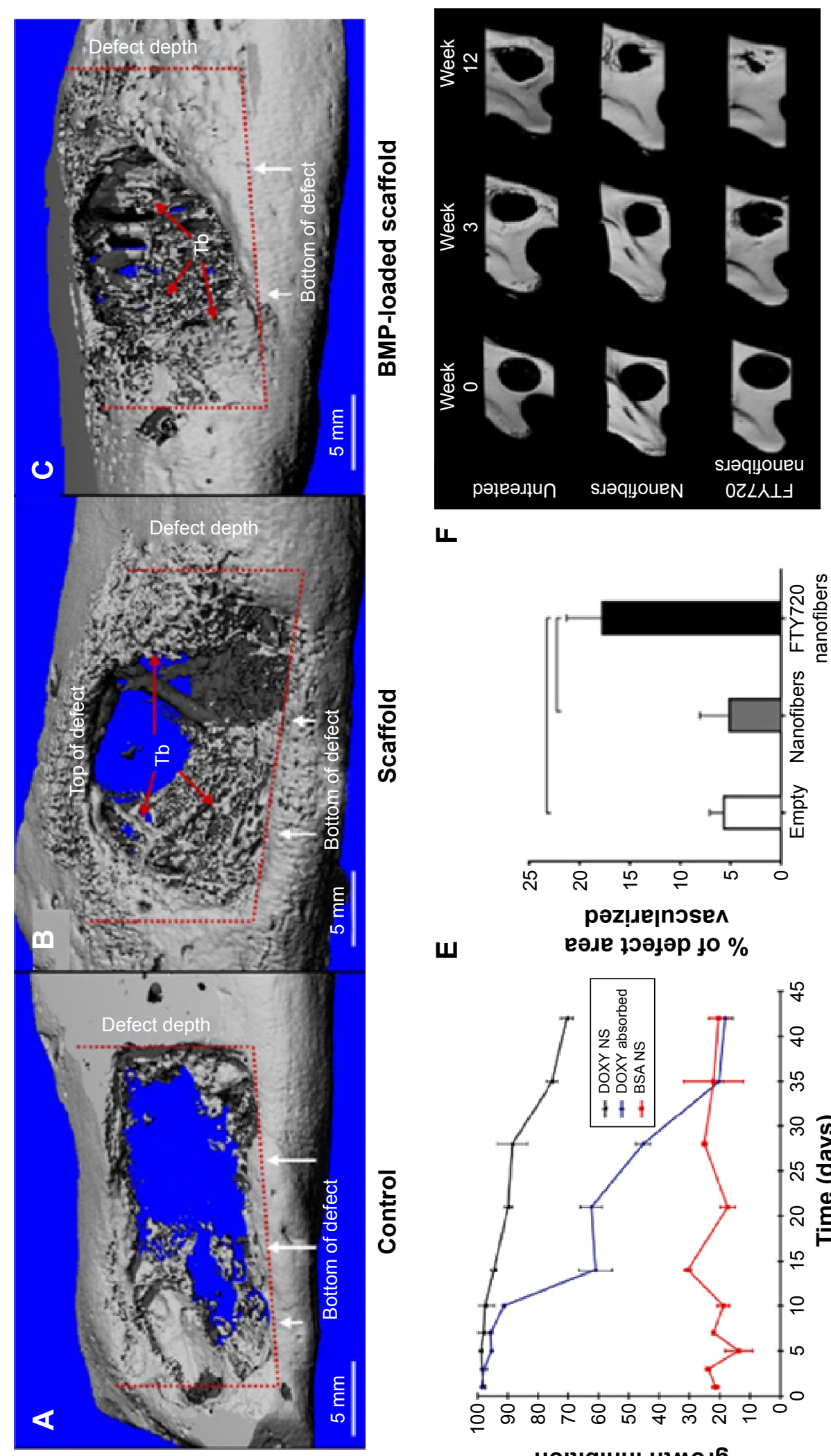

ᄂ
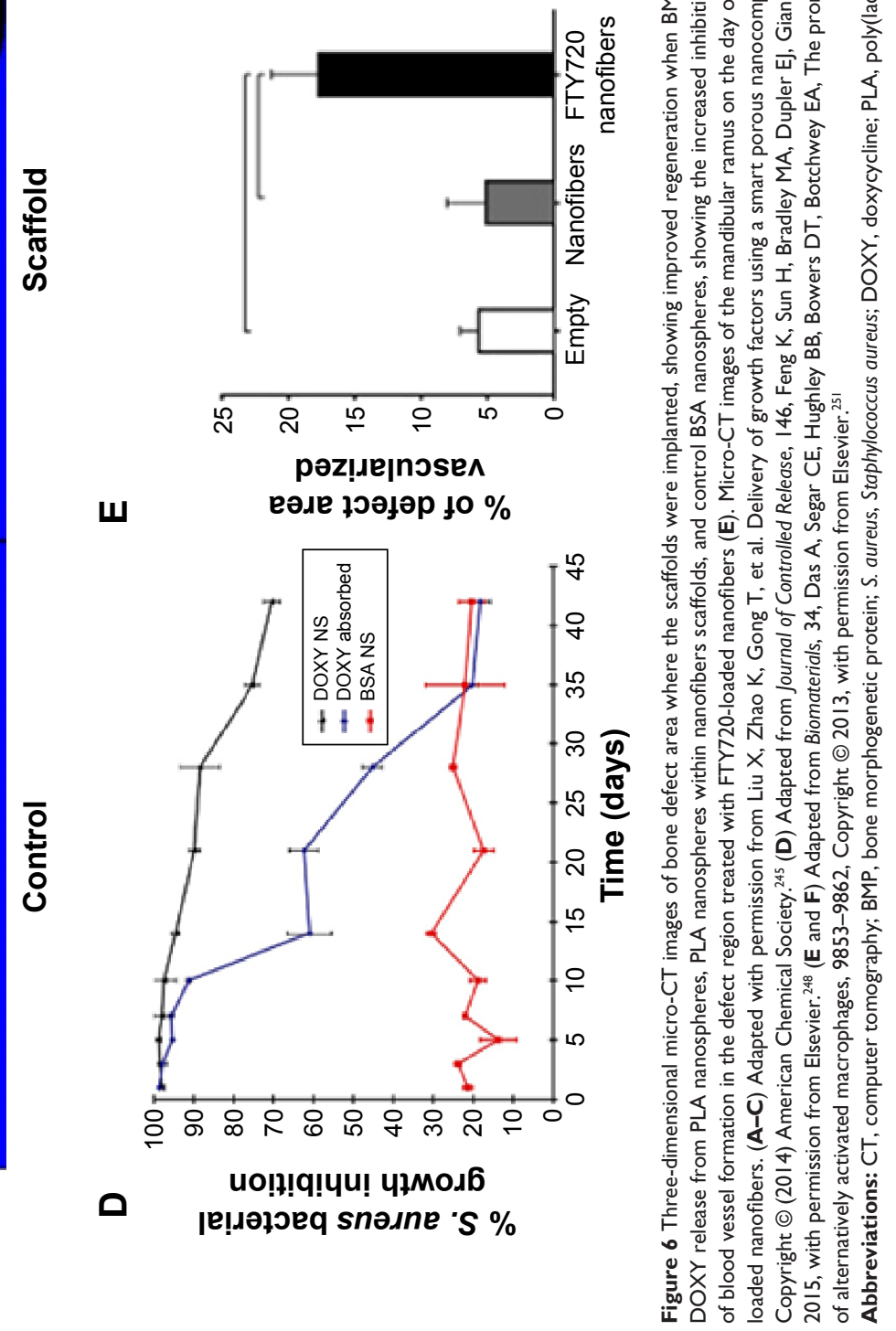
antibacterial drugs, which proved to be a good candidate for regenerative endodontics. ${ }^{249}$ In order to regenerate pulp and dentin, self-assembling peptide nanofibers encapsulating fibroblast growth factor, TGF- $\beta 1$ and vascular endothelial growth factor, and dental pulp stem cells were used. These constructs led to the formation of vascularized connective tissues similar to dental pulp when implanted into immunocompromised mice. ${ }^{250}$ In an elegant study for the mandibular reconstruction, PLGA nanofibers-incorporated FTY720, which is a targeted agonist of S1P receptors 1 and 3 and is used as a cell recruiter to enhance bone regeneration, was explored (Figure 6E and F). ${ }^{251}$ The in vivo results showed that the loaded nanofibers were able to enhance blood vessel growth and the recruitment of macrophages, therefore proving their ability to regenerate critical size defects by recruiting specific macrophages and bone healing cells. ${ }^{251}$

Collectively, the delivery of therapeutic molecules, including drugs, growth factors, and genes, has been realized in the disease treatment or repair of dental tissues, with the use of different types of nanomaterials, including nanotopological scaffolds, nanoparticulate carriers, or combination of them. For the controllable and effective delivery of these bioactive molecules and the physicochemical properties of the carrier materials, the loading and compartment of the cargo molecules should be controlled at the molecular level, which ultimately is in great need of nanotechnology and nanoscale tailoring approach.

\section{Concluding remarks}

It can be seen that nanotechnology has been exploited in dentistry for some time, particularly in the development of restorative materials, with some significant success. Researchers have been able to overcome the technical challenges of processing these materials to exploit the properties at the nanoscale. Other areas offer significant promise, particularly in the prevention and treatment of oral biofilms. One point to note in the treatment of biofilms is that virtually all treatments have focused on the killing of bacteria in the biofilm and yet the bacteria only account for around $20 \%$ of the mass of the biofilm. The remainder is a polysaccharide matrix, and it may be judicious to consider targeting this matrix, which holds the bacterial community together rather than the bacteria themselves. Utilization of nanotechnology for therapeutics more generally in dentistry offers significant opportunities as the requirements can be limited in their complexity and thus the therapeutic can be more readily realized. One factor that should be taken into consideration when developing nanotechnologies is the cost of the device or therapy being developed. There are numerous complex therapies being developed to treat a wide range of diseases, not only in dentistry but also in biomedicine more broadly, but they will never see clinical use as they will be too expensive to synthesize and thus too expensive for purchasers to procure. Cost is an important factor that is often forgotten in the development of new therapies and devices, but is ultimately the hurdle that will decide if it progresses or fails.

\section{Acknowledgment}

This work was partially supported by Priority Research Centers Program (grant 2009-0093829) through the National Research Foundation and Commercializations Promotion Agency for R\&D Outcomes (COMPA) funded by the Ministry of Education, Science and Technology, South Korea. One of the authors (JCK) acknowledges the financial support from the UK ESPRC (EP/L026287/1).

\section{Disclosure}

The authors declare that there are no conflicts of interest.

\section{References}

1. Yang J, Zhang Z, Men X, Xu X. Fabrication of stable, transparent and superhydrophobic nanocomposite films with polystyrene functionalized carbon nanotubes. Appl Surf Sci. 2009;255(22):9244-9247.

2. Abiodun Solanke IMF, Ajayi DM, Arigbede AO. Nanotechnology and its application in dentistry. Ann Med Health Sci Res. 2014;4(3): 171-177.

3. Mantri SS, Mantri SP. The nano era in dentistry. J Nat Sci Biol Med. 2013;4(1):39-44.

4. Singh S, Nalwa HS. Nanotechnology and health safety - toxicity and risk assessments of nanostructured materials on human health. J Nanosci Nanotechnol. 2007;7(9):3048-3070.

5. Ozer F, Blatz MB. Self-etch and etch-and-rinse adhesive systems in clinical dentistry. Compend Contin Educ Dent. 2013;34(1):12-14. [quiz 20, 30].

6. Yoshihara K, Yoshida Y, Nagaoka N, et al. Nano-controlled molecular interaction at adhesive interfaces for hard tissue reconstruction. Acta Biomater. 2010;6:3573-3582.

7. Solhi L, Atai M, Nodehi A, Imani M, Ghaemi A, Khosravi K. Poly(acrylic acid) grafted montmorillonite as novel fillers for dental adhesives: synthesis, characterization and properties of the adhesive. Dent Mater. 2012;28(4):369-377.

8. Pashley DH, Tay FR, Breschi L, et al. State of the art etch-and-rinse adhesives. Dent Mater. 2011;27(1):1-16.

9. Tjäderhane L, Nascimento FD, Breschi L, et al. Optimizing dentin bond durability: control of collagen degradation by matrix metalloproteinases and cysteine cathepsins. Dent Mater. 2013;29(1):116-135.

10. Scaffa PM, Vidal CM, Barros N, et al. Chlorhexidine inhibits the activity of dental cysteine cathepsins. J Dent Res. 2012;91(4):420-425.

11. Van Landuyt KL, De Munck J, Mine A, Cardoso MV, Peumans M, Van Meerbeek B. Filler debonding and subhybrid-layer failures in self-etch adhesives. J Dent Res. 2010;89(10):1045-1050.

12. Malacarne-Zanon J, de Andrade E Silva SM, Wang L, et al. Permeability of dental adhesives - a SEM assessment. Eur J Dent. 2010;4(4): 429-439.

13. Hashimoto M, De Munck J, Ito S, et al. In vitro effect of nanoleakage expression on resin-dentin bond strengths analyzed by microtensile bond test, SEM/EDX and TEM. Biomaterials. 2004;25(25):5565-5574. 
14. Profeta AC, Mannocci F, Foxton RM, Thompson I, Watson TF, Sauro S. Bioactive effects of a calcium/sodium phosphosilicate on the resin-dentine interface: a microtensile bond strength, scanning electron microscopy, and confocal microscopy study. Eur J Oral Sci. 2012;120(4):353-362.

15. Lohbauer U, Wagner A, Belli R, et al. Zirconia nanoparticles prepared by laser vaporization as fillers for dental adhesives. Acta Biomater. 2010;6(12):4539-4546.

16. Wagner A, Belli R, Stotzel C, Hilpert A, Muller FA, Lohbauer U. Biomimetically- and hydrothermally-grown HAp nanoparticles as reinforcing fillers for dental adhesives. $J$ Adhes Dent. 2013;15(5):413-422.

17. Di Hipolito V, Reis AF, Mitra SB, de Goes MF. Interaction morphology and bond strength of nanofilled simplified-step adhesives to acid etched dentin. Eur J Dent. 2012;6(4):349-360.

18. Morães RR, Garcia JW, Wilson ND, et al. Improved dental adhesive formulations based on reactive nanogel additives. $J$ Dent Res. 2012;91(2):179-184

19. Chiang YS, Chen YL, Chuang SF, et al. Riboflavin-ultraviolet-Ainduced collagen cross-linking treatments in improving dentin bonding Dent Mater. 2013;29(6):682-692.

20. dos Santos PH, Karol S, Bedran-Russo AK. Nanomechanical properties of biochemically modified dentin bonded interfaces. J Oral Rehabil. 2011;38(7):541-546

21. Bedran-Russo AK, Yoo KJ, Ema KC, Pashley DH. Mechanical properties of tannic-acid-treated dentin matrix. J Dent Res. 2009;88(9): 807-811.

22. Daood U, Iqbal K, Nitisusanta LI, Fawzy AS. Effect of chitosan/riboflavin modification on resin/dentin interface: spectroscopic and microscopic investigations. J Biomed Mater Res A. 2013;101(7):1846-1856.

23. Liu RR, Fang M, Zhao SJ, Li F, Shen LJ, Chen JH. [The potential effect of proanthocyanidins on the stability of resin-dentin bonds against thermal cycling]. Zhonghua Kou Qiang Yi Xue Za Zhi. 2012;47(5): 268-272. Chinese.

24. Tay FR, Pashley DH. Biomimetic remineralization of resin-bonded acid-etched dentin. J Dent Res. 2009;88(8):719-724.

25. Ryou H, Niu LN, Dai L, et al. Effect of biomimetic remineralization on the dynamic nanomechanical properties of dentin hybrid layers. J Dent Res. 2011;90(9):1122-1128.

26. Breschi L, Martin P, Mazzoni A, et al. Use of a specific MMP-inhibitor (galardin) for preservation of hybrid layer. Dent Mater. 2010;26(6): 571-578.

27. Almahdy A, Koller G, Sauro S, et al. Effects of MMP inhibitors incorporated within dental adhesives. J Dent Res. 2012;91(6):605-611.

28. Sabatini C. Effect of a chlorhexidine-containing adhesive on dentin bond strength stability. Oper Dent. 2013;38(6):609-617.

29. Osorio R, Yamauti M, Osorio E, et al. Effect of dentin etching and chlorhexidine application on metalloproteinase-mediated collagen degradation. Eur J Oral Sci. 2011;119(1):79-85.

30. Toledano M, Yamauti M, Ruiz-Requena ME, Osorio R. A ZnO-doped adhesive reduced collagen degradation favouring dentine remineralization. J Dent. 2012;40(9):756-765.

31. Thompson JM, Agee K, Sidow SJ, et al. Inhibition of endogenous dentin matrix metalloproteinases by ethylenediaminetetraacetic acid. J Endod. 2012;38(1):62-65.

32. De Moraes Porto IC, De Andrade AK, Alves LC, Braz R. Effect of dentin pretreatment with potassium oxalate: analysis of microtensile bond strengths and morphologic aspects. Microsc Res Tech. 2012; 75(2):239-244

33. Dundar M, Ozcan M, Comlekoglu ME, Sen BH. Nanoleakage inhibition within hybrid layer using new protective chemicals and their effect on adhesion. J Dent Res. 2011;90(1):93-98.

34. Sauro S, Mannocci F, Toledano M, Osorio R, Pashley DH, Watson TF EDTA or $\mathrm{H}_{3} \mathrm{PO}_{4} / \mathrm{NaOCl}$ dentine treatments may increase hybrid layers' resistance to degradation: a microtensile bond strength and confocalmicropermeability study. J Dent. 2009;37(4):279-288.

35. Ouyang X, Huang X, Pan Q, et al. Synthesis and characterization of triethylene glycol dimethacrylate nanocapsules used in a self-healing bonding resin. J Dent. 2011;39(12):825-833.
36. Abou Neel EA, Chrzanowski C, Young AM. Biointerfaces - Where Materials Meet Biology: Interfaces in Composite Materials. London: Royal Society of Chemistry; 2014.

37. Davies JE. Understanding peri-implant endosseous healing. J Dent Educ. 2003;67(8):932-949.

38. Bressan E, Sbricoli L, Guazzo R, et al. Nanostructured surfaces of dental implants. Int. J Mol Sci. 2013;14:1918-1931.

39. Weber HP, Fiorellini JP. The biology and morphology of the implanttissue interface. Alpha Omegan. 1992;85(4):61-64.

40. Albrektsson T, Sennerby L, Wennerberg A. State of the art of oral implants. Periodontol 2000. 2008;47:15-26.

41. Mendonça G, Mendonça DB, Aragão FJ, Cooper LF. Advancing dental implant surface technology - from micron- to nanotopography. Biomaterials. 2008;29(28):3822-3835.

42. Khan RA, Parsons AJ, Jones IA, Walker GS, Rudd CD. Degradation and interfacial properties of iron phosphate glass fiber-reinforced PCLbased composite for synthetic bone replacement materials. Polym Plast Technol. 2010;49(12):1265-1274.

43. Brammer KS, Oh S, Cobb CJ, Bjursten LM, van der Heyde H, Jin S. Improved bone-forming functionality on diameter-controlled $\mathrm{TiO} 2$ nanotube surface. Acta Biomater. 2009;5(8):3215-3223.

44. Oh S, Brammer KS, Li YS, et al. Stem cell fate dictated solely by altered nanotube dimension. Proc Natl Acad Sci U S A. 2009;106(7): 2130-2135.

45. Cavalcanti-Adam EA. Cell spreading and focal adhesion dynamics are regulated by spacing of integrin ligands. Biophys $J$ Vol. 2007;92: 2964-2974.

46. Ogawa T, Saruwatari L, Takeuchi K, Aita H, Ohno N. Ti nanonodular structuring for bone integration and regeneration. J Dent Res. 2008; 87(8):751-756.

47. Thakral G, RT NS, JS PV. Nanosurface - the future of implants. J Clin Diag Res. 2014;8(5):ZE07-ZE10.

48. Ballo A, Agheli H, Lausmaa J, Thomsen P, Petronis S. Nanostructured model implants for in vivo studies: influence of well-defined nanotopography on de novo bone formation on titanium implants. Int J Nanomedicine. 2011;6:3415-3428.

49. Aminian A, Pardun K, Volkmann E, et al. Enzyme-assisted calcium phosphate biomineralisation on an inert alumina surface. Acta Biomater. 2015;13:335-343.

50. Schliephake H, Scharnweber D, Dard M, Sewing A, Aref A, Roessler S. Functionalization of dental implant surfaces using adhesion molecules. J Biomed Mater Res B Appl Biomater. 2004;73B(1):88-96.

51. Stadlinger B, Hintze V, Bierbaum S, et al. Biological functionalization of dental implants with collagen and glycosaminoglycans - a comparative study. J Biomed Mater Res B Appl Biomater. 2012;100B(2): 331-341.

52. Lavenus S, Louarn G, Layrolle P. Nanotechnology and dental implants. Int J Biomater. 2010;2010:1-9.

53. Puleo DA, Kissling RA, Sheu MS. A technique to immobilize bioactive proteins, including bone morphogenic protein - 4 (BMP-4), on titanium alloy. Biomaterials. 2002;23:2079-2087.

54. Kloss FR, Gassner R, Preiner J, et al. The role of oxygen termination of nanocrystalline diamond on immobilization of BMP-2 and subsequent bone formation. Biomaterials. 2008;29:2433-2442.

55. Specht CG, Williams OA, Jackman RB, Schoepfer R. Ordered growth of neurons on diamond. Biomater Biomater. 2004;25:4073-4078.

56. Yoshinari M, Matsuzaka K, Inoue T. Surface modification by coldplasma technique for dental implants - bio-functionalization with binding pharmaceuticals. Jpn Dent Sci Rev. 2011;47:89-101.

57. Unosson E, Rodriguez D, Welch K, Engqvist H. Reactive combinatorial synthesis and characterization of a gradient Ag-Ti oxide thin film with antibacterial properties. Acta Biomater. 2015;11:503-510.

58. Memarzadeh K, Sharili AS, Huang J, Rawlinson SC, Allaker RP. Nanoparticulate zinc oxide as a coating material for orthopedic and dental implants. J Biomed Mater Res A. 2014;103:1-9.

59. Hanawa T. Biofunctionalization of titanium for dental implant. Jpn Dent Sci Rev. 2010;46:93-101. 
60. Gu H, Fan D, Gao J, et al. Effect of $\mathrm{ZnCl} 2$ on plaque growth and biofilm vitality. Arch Oral Biol. 2012;57(4):369-375.

61. Xie Y, He Y, Irwin PL, Jin T, Shi X. Antibacterial activity and mechanism of action of zinc oxide nanoparticles against Campylobacter jejuni. Appl Environ Microbiol. 2011;77(7):2325-2331.

62. Blecher K, Nasir A, Friedman A. The growing role of nanotechnology in combating infectious disease. Virulence. 2011;2(5):395-401.

63. Li QMS, Lyon DY, Brunet L, Liga MV, Li D, Alvarez PJ. Antimicrobial nanomaterials for water disinfection and microbial control: potential applications and implications. Water Res. 2008;42(18):4591-4602.

64. Allaker RP. The use of nanoparticles to control oral biofilm formation. J Dent Res. 2010;89(11):1175-1186.

65. Shvero DK, Davidi MP, Weiss EI, Srerer N, Beyth N. Antibacterial effect of polyethyleneimine nanoparticles incorporated in provisional cements against Streptococcus mutans. J Biomed Mater Res B Appl Biomater. 2010;94(2):367-371.

66. Kasraei S, Sami L, Hendi S, Alikhani MY, Rezaei-Soufi L, Khamverdi Z. Antibacterial properties of composite resins incorporating silver and zinc oxide nanoparticles on Streptococcus mutans and Lactobacillus. Restor Dent Endod. 2014;39(2):109-114.

67. Chen C, Weir MD, Cheng L, et al. Antibacterial activity and ion release of bonding agent containing amorphous calcium phosphate nanoparticles. Dent Mater. 2014;30(8):891-901.

68. Kawabata N, Nishiguchi M. Antibacterial activity of soluble pyridiniumtype polymers. Appl Environ Microbiol. 1998;54:2532-2535.

69. Foldbjerg R, Olesen P, Hougaard M, Dang DA, Hoffmann HJ, Autrup H. PVP-coated silver nanoparticles and silver ions induce reactive oxygen species, apoptosis and necrosis in THP-1 monocytes. Toxicol Lett. 2009; 190:156-162.

70. Song B, Leff LG. Influence of magnesium ions on biofilm formation by Pseudomonas fluorescens. Microbiol Res. 2006;161(4):355-361.

71. Rai M, Yadav A, Gade A. Silver nanoparticles as a new generation of antimicrobials. Biotechnol Adv. 2009;27:76-83.

72. das Neves PB, Agnelli JA, Kurachi C, de Souza CW. Addition of silver nanoparticles to composite resin: effect on physical and bactericidal properties in vitro. Braz Dent J. 2014;25(2):141-145.

73. Li F, Weir MD, Fouad AF, Xu HHK. Effect of salivary pellicle on antibacterial activity of novel antibacterial dental adhesives using a dental plaque microcosm biofilm model. Dent Mater. 2014;30(2): 182-191.

74. Besinis A, De Peralta T, Handy RD. Inhibition of biofilm formation and antibacterial properties of a silver nano-coating on human dentine. Nanotoxicology. 2014;8(7):745-754.

75. Lu Z, Rong K, Li J, Yang H, Chen R. Size-dependent antibacterial activities of silver nanoparticles against oral anaerobic pathogenic bacteria. J Mater Sci Mater Med. 2013;24(6):1465-1471.

76. Nakashima S, Yoshie M, Sano H, Bahar A. Effect of a test dentifrice containing nano-sized calcium carbonate on remineralization of enamel lesions in vitro. J Oral Sci. 2009;51(1):69-77.

77. Xu HH, Sun L, Weir MD, et al. Nano DCPA-whisker composites with high strength and $\mathrm{Ca}$ and $\mathrm{PO}_{4}$ release. $J$ Dent Res. 2006;85(8): $722-727$.

78. Xu HH, Weir MD, Sun L, Takagi S, Chow LC. Effects of calcium phosphate nanoparticles on $\mathrm{CaPO}_{4}$ composite. J Dent Res. 2007;86(4): 378-383.

79. Xu HH, Weir MD, Sun L. Calcium and phosphate ion releasing composite: effect of $\mathrm{pH}$ on release and mechanical properties. Dent Mater. 2009;25(4):535-542.

80. Xu HH, Sun L, Weir MD, Takagi S, Chow LC, Hockey B. Effects of incorporating nanosized calcium phosphate particles on properties of whisker-reinforced dental composites. J Biomed Mater Res B Appl Biomater. 2007;81(1):116-125.

81. Roveri N, Foresti E, Lelli M, et al. Synthetic biomimetic carbonate hydroxyapatite nanocrystals for enamel remineralization. Adv Mater Res. 2008;4(7-50):821-824.

82. Talwar GP, Diwan M, Razvi F, Malhotra R. The impact of new technologies on vaccines. Natl Med J India. 1999;12(6):274-280.
83. Wang J, Liu JG, Jiang J, Wang W, Bai GH, Guan XY. Study on gene vaccine pcDNA3-PAc against dental caries by intranasal immunization in rabbits. Shanghai Kou Qiang Yi Xue. 2014;23(2):133-137.

84. Su LK, Yu F, Li ZF, Zeng C, Xu QA, Fan MW. Intranasal co-delivery of IL-6 gene enhances the immunogenicity of anti-caries DNA vaccine. Acta Pharmacol Sin. 2014;35(5):592-598.

85. Liu G, Fan M, Guo J. Efficacy of immune responses induced by anticaries DNA vaccine-loaded bacterial ghost in mice. Zhonghua Kou Qiang Yi Xue Za Zhi. 2014;49(1):37-41.

86. Guo JH, Jia R, Fan MW, Bian Z, Chen Z, Peng B. Construction and immunogenic characterization of a fusion anti-caries DNA vaccine against PAc and glucosyltransferase I of Streptococcus mutans. J Dent Res. 2004;83(3):260-270.

87. Kt S, Kmk M, N B, Jimson S, R S. Dental caries vaccine - a possible option? J Clin Diagn Res. 2013;7(6):1250-1253.

88. Koga T, Okahashi N, Takahashi I, Kanamoto T, Asakawa H, Iwaki M. Surface hydrophobicity, adherence, and aggregation of cell surface protein antigen mutants of Streptococcus mutans Serotype c. Infect Immun. 1990;58(2):289-296.

89. Yamashita Y, Bowen WH, Burne RA, Kuramitsu HK. Role of the Streptococcus mutans gtf genes in caries induction in the specificpathogen-free rat model. Infect Immun. 1993;61(9):3811-3817.

90. Chen L, Zhu J, Li Y, et al. Enhanced nasal mucosal delivery and immunogenicity of anti-caries DNA vaccine through incorporation of anionic liposomes in chitosan/DNA complexes. PLoS One. 2013;8(8): e71953,71951-71913.

91. Hannig M, Hannig C. Nanotechnology and its role in caries therapy. Adv Dent Res. 2012;24(2):53-57.

92. Botelho MA, Martins JG, Ruela RS, Queiroz DB, Ruela WS. Nanotechnology in ligature-induced periodontitis: protective effect of a doxycycline gel with nanoparticules. J Appl Oral Sci. 2010; 18(4):335-342.

93. Saravana KR, Vijayalakshmi R. Nanotechnology in dentistry. Ind $J$ Dent Res. 2006;17:62-65.

94. Subramani K, Jung RE, Molenberg A, Hammerle CH. Biofilm on dental implants: a review of the literature. Int J Oral Maxillofac Implants. 2009;24(4):616-626.

95. Abe Y, Skali-Lami S, Block JC, Francius G. Cohesiveness and hydrodynamic properties of young drinking water biofilms. Water Res. 2012;46(4):1155-1166.

96. Yang X, Yang W, Wang Q, et al. Atomic force microscopy investigation of the characteristic effects of silver ions on Escherichia coli and Staphylococcus epidermidis. Talanta. 2010;81(4-5):1508-1512.

97. Pinzon-Arango PA, Nagarajan R, Camesano TA. Effects of L-alanine and inosine germinants on the elasticity of Bacillus anthracis spores. Langmuir. 2010;26(9):6535-6541.

98. Zhang T, Chao Y, Shih K, Li XY, Fang HH. Quantification of the lateral detachment force for bacterial cells using atomic force microscope and centrifugation. Ultramicroscopy. 2011;111(2):131-139.

99. McKendry RA. Nanomechanics of superbugs and superdrugs: new frontiers in nanomedicine. Biochem Soc Trans. 2012;40(4):603-608.

100. Longo G, Rio LM, Roduit C, et al. Force volume and stiffness tomography investigation on the dynamics of stiff material under bacterial membranes. J Mol Recognit. 2012;25(5):278-284.

101. Sullan RM, Beaussart A, Tripathi P, et al. Single-cell force spectroscopy of pili-mediated adhesion. Nanoscale. 2014;6(2):1134-1143.

102. An YH, Friedman RJ. Concise review of mechanisms of bacterial adhesion to biomaterial surfaces. J Biomed Mater Res. 1998;43(3): $338-348$.

103. Bushnak IA, Labeed FH, Sear RP, Keddie JL. Adhesion of microorganisms to bovine submaxillary mucin coatings: effect of coating deposition conditions. Biofouling. 2010;26(4):387-397.

104. Hojo K, Nagaoka S, Ohshima T, Maeda N. Bacterial interactions in dental biofilm development. J Dent Res. 2009;88(11):982-990.

105. Zhao G, Usui ML, Lippman SI, et al. Biofilms and inflammation in chronic wounds. Adv Wound Care (New Rochelle). 2013;2(7): 389-399. 
106. Costerton JW,LewandowskiZ,CaldwellDE,KorberDR,LappinscottHM. Microbial biofilms. Anпи Rev Microbiol. 1995;49:711-745.

107. Hassett DJ, Sutton MD, Schurr MJ, Herr AB, Caldwell CC, Matu JO. Pseudomonas aeruginosa hypoxic or anaerobic biofilm infections within cystic fibrosis airways. Trends Microbiol. 2009;17(3):130-138.

108. Hall-Stoodley L, Stoodley P. Evolving concepts in biofilm infections. Cell Microbiol. 2009;11(7):1034-1043.

109. Van Acker H, Van Dijck P, Coenye T. Molecular mechanisms of antimicrobial tolerance and resistance in bacterial and fungal biofilms. Trends Microbiol. 2014;22(6):326-333.

110. Younes JA, van der Mei HC, van den Heuvel E, Busscher HJ, Reid G. Adhesion forces and coaggregation between vaginal staphylococci and lactobacilli. PLoS ONE [Electronic Resource]. 2012;7(5): e36917.

111. Florin E-L, Moy VT, Gaub HE. Adhesion forces between individual ligand-receptor pairs. Science. 1994;264(5157):415-417.

112. Wessel SW, Chen Y, Maitra A, et al. Adhesion forces and composition of planktonic and adhering oral microbiomes. J Dent Res. 2014;93(1): $84-88$.

113. Formosa C, Grare M, Jauvert E, et al. Nanoscale analysis of the effects of antibiotics and CX1 on a Pseudomonas aeruginosa multidrugresistant strain. Sci Rep. 2012;2:575.

114. Popovtzer R, Agrawal A, Kotov NA, et al. Targeted gold nanoparticles enable molecular CT imaging of cancer. Nano Lett. 2008;8(12): 4593-4596.

115. Reuveni T, Motiei M, Romman Z, Popovtzer A, Popovtzer R. Targeted gold nanoparticles enable molecular CT imaging of cancer: an in vivo study. Int J Nanomedicine. 2011;6:2859-2864.

116. Turkevich J, Stevenson PC, Hillier J. A study of the nucleation and growth processes in the synthesis of colloidal gold. Discuss Faraday Soc. 1951;11:55.

117. Brust M, Walker M, Bethell D, Schiffrin DJ, Whyman R. Synthesis of thiol-derivatised gold nanoparticles in a two-phase liquid-liquid system. J Chem Soc Chem Comm. 1994;7:801-802.

118. Hainfeld JF, O'Connor MJ, Dilmanian FA, Slatkin DN, Adams DJ, Smilowitz HM. Micro-CT enables microlocalisation and quantification of HER2-targeted gold nanoparticles within tumour regions. $\mathrm{Br}$ J Radiol. 2011;84(1002):526-533.

119. Hainfeld JF, Slatkin DN, Smilowitz HM. The use of gold nanoparticles to enhance radiotherapy in mice. Phys Med Biol. 2004;49(18): N309-N315.

120. Cho WS, Cho M, Jeong J, et al. Size-dependent tissue kinetics of PEG-coated gold nanoparticles. Toxicol Appl Pharmacol. 2010;245(1): 116-123.

121. Marega R, Karmani L, Flamant L, et al. Antibody-functionalized polymer-coated gold nanoparticles targeting cancer cells: an in vitro and in vivo study. J Mater Chem. 2012;22(39):21305-21312.

122. Dixit V, Van den Bossche J, Sherman DM, Thompson DH, Andres RP. Synthesis and grafting of thioctic acid-PEG-folate conjugates onto $\mathrm{Au}$ nanoparticles for selective targeting of folate receptor-positive tumor cells. Bioconjug Chem. 2006;17(3):603-609.

123. Sudimack J, Lee RJ. Targeted drug delivery via the folate receptor. Adv Drug Deliv Rev. 2000;41(2):147-162.

124. Kim K, Huang S-W, Ashkenazi S, et al. Photoacoustic imaging of early inflammatory response using gold nanorods. Appl Phys Lett. 2007;90:22

125. Chan WCW, Nie SM. Quantum dot bioconjugates for ultrasensitive nonisotopic detection. Science. 1998;281(5385):2016-2018.

126. Kloepfer JA, Mielke RE, Wong MS, Nealson KH, Stucky G, Nadeau JL. Quantum dots as strain- and metabolism-specific microbiological labels. Appl Environ Microbiol. 2003;69(7):4205-4213.

127. Bruchez M, Moronne M, Gin P, Weiss S, Alivisatos AP. Semiconductor nanocrystals as fluorescent biological labels. Science. 1998;281(5385): 2013-2016.

128. Månsson A, Sundberg M, Balaz M, et al. In vitro sliding of actin filaments labelled with single quantum dots. Biochem Biophys Res Commun. 2004;314(2):529-534.
129. Zhu L, Ang S, Liu WT. Quantum dots as a novel immunofluorescent detection system for Cryptosporidium parvum and Giardia lamblia. Appl Environ Microbiol. 2004;70(1):597-598.

130. Goldman ER, Balighian ED, Mattoussi H, et al. Avidin: a natural bridge for quantum dot-antibody conjugates. J Am Chem Soc. 2002;124(22): 6378-6382.

131. Jaiswal JK, Mattoussi H, Mauro JM, Simon SM. Long-term multiple color imaging of live cells using quantum dot bioconjugates. Nat Biotechnol. 2003;21(1):47-51.

132. Dubertret B, Skourides P, Norris DJ, Noireaux V, Brivanlou AH, Libchaber A. In vivo imaging of quantum dots encapsulated in phospholipid micelles. Science. 2002;298(5599):1759-1762.

133. Xiao Y, Barker PE. Semiconductor nanocrystal probes for human metaphase chromosomes. Nucleic Acids Res. 2004;32:3.

134. Xu H, Sha MY, Wong EY, et al. Multiplexed SNP genotyping using the Qbead (TM) system: a quantum dot-encoded microsphere-based assay. Nucleic Acids Res. 2003;31:8.

135. Akerman ME, Chan WCW, Laakkonen P, Bhatia SN, Ruoslahti E. Nanocrystal targeting in vivo. Proc Natl Acad Sci US A. 2002;99(20): $12617-12621$.

136. Rosenthal SJ, Tomlinson I, Adkins EM, et al. Targeting cell surface receptors with ligand-conjugated nanocrystals. $\mathrm{J} \mathrm{Am} \mathrm{Chem} \mathrm{Soc.}$ 2002;124(17):4586-4594.

137. Kloepfer JA, Mielke RE, Nadeau JL. Uptake of CdSe and CdSe/ZnS quantum dots into bacteria via purine-dependent mechanisms. Appl Environ Microbiol. 2005;71(5):2548-2557.

138. Parkin DM, Bray F, Ferlay J, Pisani P. Global cancer statistics, 2002. CA Cancer J Clin. 2005;55(2):74-108.

139. Seiwert TY, Cohen EE. State-of-the-art management of locally advanced head and neck cancer. Br J Cancer. 2005;92(8):1341-1348.

140. Yang CC, Hung PS, Wang PW, et al. miR-181 as a putative biomarker for lymph-node metastasis of oral squamous cell carcinoma. J Oral Pathol Med. 2011;40(5):397-404.

141. Bhirde AA, Patel V, Gavard J, et al. Targeted killing of cancer cells in vivo and in vitro with EGF-directed carbon nanotube-based drug delivery. ACS Nano. 2009;3(2):307-316.

142. Malhotra R, Patel V, Vaque JP, Gutkind JS, Rusling JF. Ultrasensitive electrochemical immunosensor for oral cancer biomarker IL-6 using carbon nanotube forest electrodes and multilabel amplification. Anal Chem. 2010;82(8):3118-3123.

143. Bianco A, Kostarelos K, Partidos CD, Prato M. Biomedical applications of functionalised carbon nanotubes. Chem Commun. 2005;5:571-577.

144. Chen RJ, Bangsaruntip S, Drouvalakis KA, et al. Noncovalent functionalization of carbon nanotubes for highly specific electronic biosensors. Proc Natl Acad Sci U S A. 2003;100(9):4984-4989.

145. Singh R, Pantarotto D, McCarthy D, et al. Binding and condensation of plasmid DNA onto functionalized carbon nanotubes: toward the construction of nanotube-based gene delivery vectors. J Am Chem Soc. 2005;127(12):4388-4396.

146. Kam NWS, Dai HJ. Carbon nanotubes as intracellular protein transporters: generality and biological functionality. $\mathrm{J} \mathrm{Am} \mathrm{Chem} \mathrm{Soc.} \mathrm{2005;}$ 127(16):6021-6026.

147. Pantarotto D, Briand JP, Prato M, Bianco A. Translocation of bioactive peptides across cell membranes by carbon nanotubes. Chem Commun. 2004;1:16-17.

148. Singh R, Pantarotto D, Lacerda L, et al. Tissue biodistribution and blood clearance rates of intravenously administered carbon nanotube radiotracers. Proc Natl Acad Sci U S A. 2006;103(9):3357-3362.

149. Otsuka Y, Hanaki K, Zhao JZ, et al. Detection of Mycobacterium bovis bacillus Calmette-Guerin using quantum dot immuno-conjugates. Jpn J Infect Dis. 2004;57(4):183-184.

150. Su XL, Li YB. Quantum dot biolabeling coupled with immunomagnetic separation for detection of Escherichia coli O157: H7. Anal Chem. 2004;76(16):4806-4810.

151. Wu X, Liu H, Liu J, et al. Immunofluorescent labeling of cancer marker Her2 and other cellular targets with semiconductor quantum dots. Nat Biotechnol. 2003;21(4):452-452. 
152. Yang LJ, Li YB. Simultaneous detection of Escherichia coli O157: H7 and Salmonella Typhimurium using quantum dots as fluorescence labels. Analyst. 2006;131(3):394-401.

153. Chalmers NI, Palmer RJ, Du-Thumm L, Sullivan R, Shi W, Kolenbrander PE. Use of quantum dot luminescent probes to achieve single-cell resolution of human oral bacteria in biofilms. Appl Environ Microbiol. 2007;73(2):630-636.

154. Li Y, Denny P, Ho CM, et al. The Oral Fluid MEMS/NEMS Chip (OFMNC): diagnostic and translational applications. Adv Dent Res. 2005;18(1):3-5.

155. Yager P, Edwards T, Fu E, et al. Microfluidic diagnostic technologies for global public health. Nature. 2006;442(7101):412-418.

156. Herr AE, Hatch AV, Throckmorton DJ, et al. Microfluidic immunoassays as rapid saliva-based clinical diagnostics. Proc Natl Acad Sci US A. 2007;104(13):5268-5273.

157. Segal A, Wong DT. Salivary diagnostics: enhancing disease detection and making medicine better. Eur J Dent Educ. 2008;12:22-29.

158. Huang T, Shalci A, Ho D, Zhang YH, McCabe ERB, Ho CM. Rapid bacterial diagnosis: MEMS-based DNA detection. Pediatr Res. 2002; 51(4):276A-277A.

159. Soong RK, Bachand GD, Neves HP, Olkhovets AG, Craighead HG, Montemagno CD. Powering an inorganic nanodevice with a biomolecular motor. Science. 2000;290(5496):1555-1558.

160. Gau V, Wong D. Oral fluid nanosensor test (OFNASET) with advanced electrochemical-based molecular analysis platform. Ann N Y Acad Sci. 2007;1098:401-410.

161. Yoshizawa JM, Wong DT. Salivary microRNAs and oral cancer detection. Methods Mol Biol. 2013;936:313-324.

162. Fuentes L, Yakob M, Wong DTW. Emerging horizons of salivary diagnostics for periodontal disease. Br Dent J. 2014;217(10): $567-573$.

163. Liu CJ, Kao SY, Tu HF, Tsai MM, Chang KW, Lin SC. Increase of microRNA miR-31 level in plasma could be a potential marker of oral cancer. Oral Dis. 2010;16:360-364.

164. Chen CRD, Broomer AJ, Zhou Z, et al. Real-time quantification of microRNAs by stem-loop RT-PCR. Nucleic Acids Res. 2005; 33:e179.

165. Shi R, Chiang VL. Facile means for quantifying microRNA expression by real-time PCR. Biotechniques. 2005;39:519-525.

166. Li W, Ruan K. MicroRNA detection by microarray. Anal Bioanal Chem. 2009;394:1117-1124.

167. Yin JQ, Zhao RC, Morris KV. Profiling microRNA expression with microarrays. Trends Biotechnol. 2008;26:70-76.

168. Mestdagh P, Feys T, Bernard N, et al. High-throughput stem-loop RT-qPCR miRNA expression profiling using minute amounts of input RNA. Nucleic Acids Res. 2008;36:e143.

169. Schmittgen TD, Lee EJ, Jiang J, et al. Real-time PCR quantification of precursor and mature microRNA. Methods. 2008;44:31-38.

170. Weigum SE, Floriano PN, Redding SW, et al. Nano-bio-chip sensor platform for examination of oral exfoliative cytology. Cancer Prev Res. 2010;3(4):518-528.

171. Weigum SE, Floriano PN, Christodoulides N, McDevitt JT. Cell-based sensor for analysis of EGFR biomarker expression in oral cancer. $L a b$ Chip. 2007;7(8):995-1003.

172. Christodoulides N, Mohanty S, Miller CS, et al. Application of microchip assay system for the measurement of C-reactive protein in human saliva. Lab Chip. 2005;5(3):261-269.

173. Pasceri V, Willerson JT, Yeh ET. Direct proinflammatory effect of C-reactive protein on human endothelial cells. Circulation. 2000;102(18): 2165-2168.

174. Joshipura KJ, Wand HC, Merchant AT, Rimm EB. Periodontal disease and biomarkers related to cardiovascular disease. J Dent Res. 2004;83(2):151-155.

175. Loos BG, Craandijk J, Hoek FJ, Wertheim-van Dillen PME, van der Velden U. Elevation of systemic markers related to cardiovascular disease in the peripheral blood of periodontitis patients. J Periodontol. 2000;71(10):1528-1534.
176. Pederson ED, Stanke SR, Whitener SJ, Sebastiani PT, Lamberts BL, Turner DW. Salivary levels of alpha(2)-macroglobulin, alpha(1)antitrypsin, C-reactive protein, cathepsin $\mathrm{G}$ and elastase in humans with or without destructive periodontal disease. Arch Oral Biol. 1995; 40(12):1151-1155.

177. Christodoulides N, Floriano PN, Miller CS, et al. Lab-on-a-chip methods for point-of-care measurements of salivary biomarkers of periodontitis. Ann N Y Acad Sci. 2007;1098:411-428.

178. Milovanovic M, Nilsson E, Jaremo P. Relationships between platelets and inflammatory markers in rheumatoid arthritis. Clin Chim Acta. 2004;343(1-2):237-240.

179. Ridker PM, Glynn RJ, Hennekens CHC. Reactive protein adds to the predictive value of total and HDL cholesterol in determining risk of first myocardial infarction. Circulation. 1998;97(20):2007-2011.

180. Ridker PM, Stampfer MJ, Rifai N. Novel risk factors for systemic atherosclerosis - a comparison of C-reactive protein, fibrinogen, homocysteine, lipoprotein(a), and standard cholesterol screening as predictors of peripheral arterial disease. JAMA. 2001;285(19):2481-2485.

181. Herr AE, Hatch AV, Giannobile WV, et al. Integrated microfluidic platform for oral diagnostics. Ann N Y Acad Sci. 2007;1098:362-374.

182. Irwin CR, Myrillas TT. The role of IL- 6 in the pathogenesis of periodontal disease. Oral Dis. 1998;4(1):43-47.

183. Fine DH, Markowitz K, Furgang D, et al. Macrophage inflammatory protein-1 alpha: a salivary biomarker of bone loss in a longitudinal cohort study of children at risk for aggressive periodontal disease? J Periodontol. 2009;80(1):106-113.

184. Ng PY, Donley M, Hausmann E, Hutson AD, Rossomando EF, Scannapieco FA. Candidate salivary biomarkers associated with alveolar bone loss: cross-sectional and in vitro studies. FEMS Immunol Med Microbiol. 2007;49(2):252-260.

185. Liu CHC. Filling in dentinal tubules. Nanotechnology. 2007;18: 475104.

186. Freitas RA Jr. Nanodentistry. J Am Dent Assoc. 2000;131(11): 1559-1566.

187. Kishen A, Shi Z, Shrestha A, Neoh KG. An investigation on the antibacterial and antibiofilm efficacy of cationic nanoparticulates for root canal disinfection. J Endod. 2008;34(12):1515-1520.

188. Monzavi A, Eshraghi S, Hashemian R, Momen-Heravi F. In vitro and ex vivo antimicrobial efficacy of nano- $\mathrm{MgO}$ in the elimination of endodontic pathogens. Clin Oral Investig. 2015;19(2):349-356.

189. Zhang XD, Wu D, Shen X, et al. Size-dependent radiosensitization of PEG-coated gold nanoparticles for cancer radiation therapy. Biomaterials. 2012;33(27):6408-6419.

190. Sulfikkarali N, Krishnakumar N, Manoharan S, Nirmal RM. Chemopreventive Efficacy of Naringenin-Loaded Nanoparticles in 7,12-dimethylbenz(a)anthracene Induced Experimental Oral Carcinogenesis. Pathol Oncol Res. 2013;19:287-296.

191. Kang B, Mackey MA, El-Sayed MA. Nuclear targeting of gold nanoparticles in cancer cells induces DNA damage, causing cytokinesis arrest and apoptosis. J Am Chem Soc. 2010;132(5):1517-1519.

192. Mackey MA, Saira F, Mahmoud MA, El-Sayed MA. Inducing cancer cell death by targeting its nucleus: solid gold nanospheres versus hollow gold nanocages. Bioconjug Chem. 2013;24(6):897-906.

193. Wu YN, Yang LX, Shi XY, et al. The selective growth inhibition of oral cancer by iron core-gold shell nanoparticles through mitochondriamediated autophagy. Biomaterials. 2011;32(20):4565-4573.

194. Sprintz M, Benedetti C, Ferrari M. FERRARI Applied nanotechnology for the management of breakthrough cancer pain. Minerva Anestesiol. 2005;71:419-423.

195. Langer R, Vacanti JP. Tissue engineering. Science. 1993;260: 920-926.

196. Chan BP, Leong KW. Scaffolding in tissue engineering: general approaches and tissue-specific considerations. Eur Spine J. 2008; 17(suppl 4):467-479.

197. Balasundaram G, Webster TJ. Nanotechnology and biomaterials for orthopedic medical applications. Nanomedicine (Lond). 2006; 1:169-176. 
198. Shi J, Votruba AR, Farokhzad OC, Langer R. Nanotechnology in drug delivery and tissue engineering: from discovery to applications. Nano Lett. 2010;10:3223-3230.

199. Hartgerink JD, Beniash E, Stupp SI. Self-assembly and mineralization of peptide-amphiphile nanofibers. Science. 2001;294: 1684-1688.

200. Song J, Malathong V, Bertozzi CR. Mineralization of synthetic polymer scaffolds: a bottom-up approach for the development of artificial bone. J Am Chem Soc. 2005;127:3366-3372.

201. Du C, Falini G, Fermani S, Abbott C, Moradian-Oldak J. Supramolecular assembly of amelogenin nanospheres into birefringent microribbons. Science. 2005;307:1450-1454.

202. He G, Dahl T, Veis A, George A. Nucleation of apatite crystals in vitro by self-assembled dentin matrix protein 1. Nat Mater. 2003;2: $552-558$.

203. Inanç B, Arslan YE, Seker S, Elçin AE, Elçin YM. Periodontal ligament cellular structures engineered with electrospun poly(DL-lactideco-glycolide) nanofibrous membrane scaffolds. J Biomed Mater Res A 2009;90:186-195.

204. Qu T, Liu X. Nano-structured gelatin/bioactive glass hybrid scaffolds for the enhancement of odontogenic differentiation of human dental pulp stem cells. J Mater Chem B Mater Biol Med. 2013;1:4764-4772.

205. Yang X, Yang F, Walboomers XF, Bian Z, Fan M, Jansen JA. The performance of dental pulp stem cells on nanofibrous PCL/gelatin/ nHA scaffolds. J Biomed Mater Res A. 2010;93:247-257.

206. Huang Z, Newcomb CJ, Bringas P Jr, Stupp SI, Snead ML. Biological synthesis of tooth enamel instructed by an artificial matrix. Biomaterials. 2010;31:9202-9211.

207. Kumada Y, Zhang S. Significant type I and type III collagen production from human periodontal ligament fibroblasts in $3 \mathrm{D}$ peptide scaffolds without extra growth factors. PLoS One. 2010;5:e10305.

208. Wang J, Liu X, Jin X, et al. The odontogenic differentiation of human dental pulp stem cells on nanofibrous poly(L-lactic acid) scaffolds in vitro and in vivo. Acta Biomater. 2010;6:3856-3863.

209. Wang J, Ma H, Jin X, et al. The effect of scaffold architecture on odontogenic differentiation of human dental pulp stem cells. Biomaterials. 2011;32:7822-7830.

210. Ganesh N, Jayakumar R, Koyakutty M, Mony U, Nair SV. Embedded silica nanoparticles in poly(caprolactone) nanofibrous scaffolds enhanced osteogenic potential for bone tissue engineering. Tissue Eng Part A. 2012;18:1867-1881.

211. Woo KM, Chen VJ, Ma PX. Nano-fibrous scaffolding architecture selectively enhances protein adsorption contributing to cell attachment J Biomed Mater Res A. 2003;67:531-537.

212. Kim GH, Park YD, Lee SY, et al. Odontogenic stimulation of human dental pulp cells with bioactive nanocomposite fiber. J Biomater Appl. 2015;29:854-866.

213. Deng XL, Xu MM, Li D, Sui G, Hu XY, Yang XP. Electrospun PLLA/ MWNTs/HA Hybrid Nanofiber Scaffolds and Their Potential in Dental Tissue Engineering. Key Eng. Mater. 2007;33(0-332):393-396.

214. Xu MM, Mei F, Li D, et al. Electrospun Poly(L-lacticacid)/NanoHydroxyapatite Hybrid Nanofibers and Their Potential in Dental Tissue Engineering. Key Eng Mater. 2007;33(0-332):377-380.

215. Besinis A, van Noort R, Martin N. Infiltration of demineralized dentin with silica and hydroxyapatite nanoparticles. Dent Mater. 2012; 28:1012-1023

216. Qu T, Jing J, Jiang Y, et al. Magnesium-containing nanostructured hybrid scaffolds for enhanced dentin regeneration. Tissue Eng Part A. 2014;20:2422-2433.

217. Galler KM, Cavender A, Yuwono V, et al. Self-assembling peptide amphiphile nanofibers as a scaffold for dental stem cells. Tissue Eng Part A. 2008;14:2051-2058.

218. Vallés-Lluch A, Novella-Maestre E, Sancho-Tello M, Pradas MM, Ferrer GG, Batalla CC. Mimicking natural dentin using bioactive nanohybrid scaffolds for dentinal tissue engineering. Tissue Eng Part A. 2010;16(9):2783-2793.
219. Fletcher J, Dominic W, Emma Fowler C, Mann S. Electrospun mats of PVP/ACP nanofibres for remineralization of enamel tooth surfaces. Cryst Eng Comm. 2011;13:3692.

220. Zhang S, Huang Y, Yang X, et al. Gelatin nanofibrous membrane fabricated by electrospinning of aqueous gelatin solution for guided tissue regeneration. J Biomed Mater Res A. 2009;90:671-679.

221. Shalumon KT, Sowmya S, Sathish D, Chennazhi KP, Nair SV, Jayakumar R. Effect of incorporation of nanoscale bioactive glass and hydroxyapatite in PCL/chitosan nanofibers for bone and periodontal tissue engineering. J Biomed Nanotechnol. 2013;9:430-440.

222. He H, Yu J, Cao J, et al. Biocompatibility and osteogenic capacity of periodontal ligament stem cells on $\mathrm{nHAC} / \mathrm{PLA}$ and HA/TCP scaffolds. J Biomater Sci Polym Ed. Epub 2010 Jun 16.

223. Yang CL, Lee JS, Jung UW, Seo YK, Park JK, Choi SH. Periodontal regeneration with nano-hyroxyapatite-coated silk scaffolds in dogs. J Periodontal Implant Sci. 2013;43:315-322.

224. Srinivasan SJR, Chennazhi KP, Nair SV, Jayakumar R. Biocompatible alginate/nano bioactive glass ceramic composite scaffolds for periodontal tissue regeneration. Carbohydr Polym. 2012;87:274-283.

225. Guo J, Meng Z, Chen G, et al. Restoration of critical-size defects in the rabbit mandible using porous nanohydroxyapatite-polyamide scaffolds. Tissue Eng Part A. 2012;18:1239-1252.

226. Zhang X, Xu M, Liu X, et al. Restoration of critical-sized defects in the rabbit mandible using autologous bone marrow stromal cells hybridized with nano- $\beta$-tricalcium phosphate/collagen scaffolds. J Nanomater. 2013;2013:1-8.

227. Kettler K, Veltman K, van Wezel A, Jan Hendriks A. Cellular uptake of nanoparticles as determined by particle properties, experimental conditions, and cell type. Environ Toxicol Chem. 2014;33:481-492.

228. Treuel L, Jiang X, Nienhaus GU. New views on cellular uptake and trafficking of manufactured nanoparticles. J R Soc Interface. 2013; 10:20120939

229. Darveau RP. Periodontitis: a polymicrobial disruption of host homeostasis. Nat Rev Microbiol. 2010;8:481-490.

230. Pragati S, Ashok S, Kuldeep S. Recent advances in periodontal drug delivery systems. Int J Drug Deliv. 2009;1:1-14.

231. Giannobile WV, Ryan S, Shih MS, Su DL, Kaplan PL, Chan TC. Recombinant human osteogenic protein-1 (OP-1) stimulates periodontal wound healing in class III furcation defects. J Periodontol. 1998;69:129-137.

232. King GN, King N, Hughes FJ. The effect of root surface demineralization on bone morphogenetic protein-2-induced healing of rat periodontal fenestration defects. J Periodontol. 1998;69:561-570.

233. Ripamonti U, Crooks J, Petit JC, Rueger DC. Periodontal tissue regeneration by combined applications of recombinant human osteogenic protein-1 and bone morphogenetic protein-2. A pilot study in Chacma baboons (Papio ursinus). Eur J Oral Sci. 2001;109:241-248.

234. Wikesjö UM, Sorensen SR, Kinoshita A, Jian Li X, Wozney JM. Periodontal repair in dogs: effect of recombinant human bone morphogenetic protein-12 (rhBMP-12) on regeneration of alveolar bone and periodontal attachment. J Clin Periodontol. 2004;31:662-670.

235. Kashi TS, Eskandarion S, Esfandyari-Manesh M, et al. Improved drug loading and antibacterial activity of minocycline-loaded PLGA nanoparticles prepared by solid/oil/water ion pairing method. Int J Nanomedicine. 2012;7:221-234.

236. Moore L, Gatica M, Kim H, Osawa E, Ho D. Multi-protein delivery by nanodiamonds promotes bone formation. J Dent Res. 2013;92: 976-981.

237. Madhumathi K, Sampath Kumar TS. Regenerative potential and antibacterial activity of tetracycline loaded apatitic nanocarriers for the treatment of periodontitis. Biomed Mater. 2014;9:035002.

238. Chen FM, Ma ZW, Dong GY, Wu ZF. Composite glycidyl methacrylated dextran (Dex-GMA)/gelatin nanoparticles for localized protein delivery. Acta Pharmacol Sin. 2009;30:485-493.

239. Elangovan S, Jain S, Tsai PC, Margolis HC, Amiji M. Nano-sized calcium phosphate particles for periodontal gene therapy. J Periodontol. 2013;84:117-125. 
240. Yang X, Walboomers XF, van den Dolder J, et al. Non-viral bone morphogenetic protein 2 transfection of rat dental pulp stem cells using calcium phosphate nanoparticles as carriers. Tissue Eng Part A. 2008;14:71-81.

241. Zhang Y, Wei L, Miron RJ, Zhang Q, Bian Z. Prevention of alveolar bone loss in an osteoporotic animal model via interference of semaphorin 4d. J Dent Res. 2014;93:1095-1100.

242. Sindhura Reddy N, Sowmya S, Bumgardner JD, Chennazhi KP, Biswas R, Jayakumar R. Tetracycline nanoparticles loaded calcium sulfate composite beads for periodontal management. Biochim Biophys Acta. 2014;1840:2080-2090.

243. Khodir WWA, Guarino V, Alvarez-Perez M, Cafiero C, Ambrosio L. Trapping tetracycline-loaded nanoparticles into polycaprolactone fiber networks for periodontal regeneration therapy. J Bioact Compat Polym. 2013;28:258-273.

244. Zhang $\mathrm{X}$, Guo WG, Cui H, et al. In vitro and in vivo enhancement of osteogenic capacity in a synthetic BMP-2 derived peptide-coated mineralized collagen composite. J Tissue Eng Regen Med. Epub 2013 Jan 31 .

245. Liu X, Zhao K, Gong T, et al. Delivery of growth factors using a smart porous nanocomposite scaffold to repair a mandibular bone defect. Biomacromolecules. 2014;15:1019-1030.
246. Liu HC, E LL, Wang DS, et al. Reconstruction of alveolar bone defects using bone morphogenetic protein 2 mediated rabbit dental pulp stem cells seeded on nano-hydroxyapatite/collagen/poly(L-lactide). Tissue Eng Part A. 2011;17:2417-2433.

247. Zamani M, Morshed M, Varshosaz J, Jannesari M. Controlled release of metronidazole benzoate from poly epsilon-caprolactone electrospun nanofibers for periodontal diseases. Eur J Pharm Biopharm. 2010;75:179-185.

248. Feng K, Sun H, Bradley MA, Dupler EJ, Giannobile WV, Ma PX. Novel antibacterial nanofibrous PLLA scaffolds. J Control Release. 2010;146:363-369.

249. Bottino MC, Kamocki K, Yassen GH, et al. Bioactive nanofibrous scaffolds for regenerative endodontics. J Dent Res. 2013;92:963-969.

250. Hartgerink JD, Cavender AC, Schmalz G, D’Souza RN. A customized self-assembling peptide hydrogel for dental pulp tissue engineering. Tissue Eng Part A. 2012;18:176-184.

251. Das A, Segar CE, Hughley BB, Bowers DT, Botchwey EA. The promotion of mandibular defect healing by the targeting of S1P receptors and the recruitment of alternatively activated macrophages. Biomaterials. 2013;34:9853-9862.
International Journal of Nanomedicine

\section{Publish your work in this journal}

The International Journal of Nanomedicine is an international, peerreviewed journal focusing on the application of nanotechnology in diagnostics, therapeutics, and drug delivery systems throughout the biomedical field. This journal is indexed on PubMed Central,

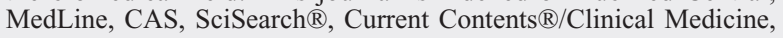

\section{Dovepress}

Journal Citation Reports/Science Edition, EMBase, Scopus and the Elsevier Bibliographic databases. The manuscript management system is completely online and includes a very quick and fair peer-review system, which is all easy to use. Visit http://www.dovepress.com/ testimonials.php to read real quotes from published authors. 